\title{
Further Studies into the Photodissociation Pathways of 2-Bromo-2- nitropropane and the Dissociation Channels of the 2-Nitro-2-propyl Radical Intermediate
}

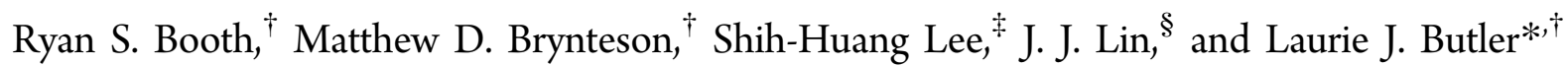 \\ ${ }^{\dagger}$ Department of Chemistry and the James Franck Institute, The University of Chicago, Chicago, Illinois 60637, United States \\ ${ }^{\ddagger}$ National Synchrotron Radiation Research Center, Hsinchu 30076, Taiwan, Republic of China \\ ${ }^{\S}$ Institute of Atomic and Molecular Sciences, Academia Sinica, Taipei 10617, Taiwan, Republic of China
}

\section{Supporting Information}

\begin{abstract}
These experiments investigate the decomposition mechanisms of geminal dinitro energetic materials by photolytically generating two key intermediates: 2-nitropropene and 2-nitro-2-propyl radicals. To characterize the unimolecular dissociation of each intermediate, we form them under collision-free conditions using the photodissociation of 2 bromo-2-nitropropane; the intermediates are formed at high internal energies and undergo a multitude of subsequent unimolecular dissociation events investigated herein. Complementing our prior work on this system, the new data obtained with a crossed-laser molecular beam scattering apparatus with VUV photoionization detection at Taiwan's National Synchrotron Radiation Research Center (NSRRC) and new velocity map imaging data better characterize two of the four primary $193 \mathrm{~nm}$ photodissociation channels. The $\mathrm{C}-\mathrm{Br}$ photofission channel forming the 2-

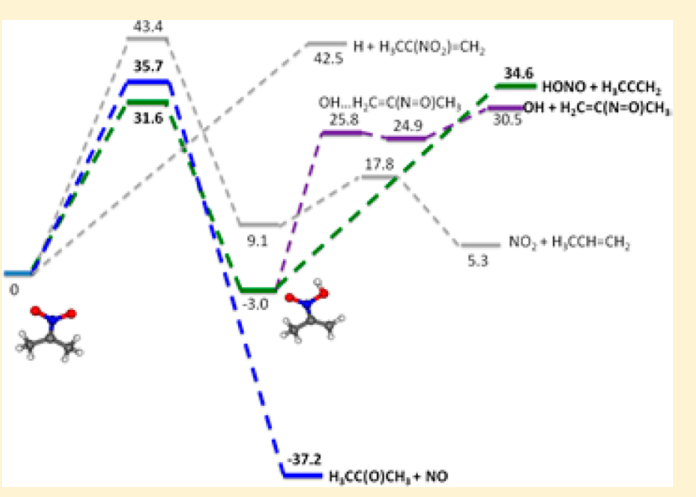
nitro-2-propyl radicals has a trimodal recoil kinetic energy distribution, $P\left(E_{\mathrm{T}}\right)$, suggesting that the 2-nitro-2-propyl radicals are formed both in the ground electronic state and in two low-lying excited electronic states. The new data also revise the $\mathrm{HBr}$ photoelimination $P\left(E_{\mathrm{T}}\right)$ forming the 2-nitropropene intermediate. We then resolved the multiple competing unimolecular dissociation channels of each photoproduct, confirming many of the channels detected in the prior study, but not all. The new data detected HONO product at $m / e=47$ using $11.3 \mathrm{eV}$ photoionization from both intermediates; analysis of the momentummatched products allows us to establish that both 2-nitro-2-propyl $\rightarrow \mathrm{HONO}+\mathrm{CH}_{3} \mathrm{CCH}_{2}$ and 2-nitropropene $\rightarrow \mathrm{HONO}+$ $\mathrm{C}_{3} \mathrm{H}_{4}$ occur. Photoionization at $9.5 \mathrm{eV}$ allowed us to detect the mass 71 coproduct formed in $\mathrm{OH}$ loss from 2-nitro-2-propyl; a channel missed in our prior study. The dynamics of the highly exothermic 2-nitro-2-propyl $\rightarrow \mathrm{NO}+$ acetone dissociation is also better characterized; it evidences a sideways scattered angular distribution. The detection of some stable 2-nitropropene photoproducts allows us to fit signal previously assigned to $\mathrm{H}$ loss from 2-nitro-2-propyl radicals. Overall, the data provide a comprehensive study of the unimolecular dissociation channels of these important nitro-containing intermediates.
\end{abstract}

\section{INTRODUCTION}

The decomposition pathways of energetic materials have been intensely studied both experimentally and theoretically for decades. $^{1-9}$ These mechanisms can be difficult to elucidate in the bulk phase, however, due to the plethora of side reactions. To this end, theoretical predictions can be used to evaluate possible steps in a proposed decomposition mechanism. For example, the recent computational study on TNAZ decomposition pathways submitted this year by Veals and Thompson ${ }^{9}$ re-examines previous computational and experimental results on TNAZ, clarifying the first few steps in the decomposition mechanism. A second potential method for studying these systems is to photolytically induce the decomposition of smaller model materials. Because a common functionality across organic based energetic materials (i.e., RDX, HMX) is nitro groups, there have been extensive studies on the photodissociation of relatively simple nitrocompounds. ${ }^{10-20}$
Although these molecules serve as good mimics of the initial dissociation for most energetic materials (i.e., singlet nitro species), some energetic materials have two nitro groups on the same carbon. These materials, such as TNAZ and FOX-7, pass through nitroalkyl radical or nitroalkene intermediates en route to their eventual decomposition products. ${ }^{7,8}$

One route to study the decomposition of key intermediates such as nitroalkyl radicals is to produce them from the photodissociation of the appropriate halogenated precursor. Creating these intermediates photolytically allows the study of these intermediates in isolated environments without the possibility of side reactions. One class of materials that have the potential to model the decomposition of such intermediates

Received: March 5, 2014

Revised: May 29, 2014

Published: June 20, 2014 
is halonitroalkanes. ${ }^{21,22}$ Studies have shown that upon irradiation with $193 \mathrm{~nm}$ photons, these materials undergo both $\mathrm{Br}$ and $\mathrm{HBr}$ loss yielding a nitroalkyl radical and a nitroalkene, respectively. ${ }^{21,22}$ Because FOX-7 is being investigated as a potential replacement material for the commonly used RDX and geminal dinitro compounds are commonly used as energetic materials, it is imperative to determine the exact mechanistic steps that these materials undergo upon decomposition.

Although halonitroalkanes promise to be useful photolytic precursors in elucidating the decomposition mechanisms of nitroalkyl radicals, the photodissociation dynamics of halonitroalkanes at $193 \mathrm{~nm}$ are extremely complicated due to the many competing primary photodissociation channels. In our previous study on 2-bromo-2-nitropropane, ${ }^{22}$ upon irradiation at $193 \mathrm{~nm}$ the molecule undergoes four photodissociation pathways, each with subsequent unimolecular dissociations. This plethora of fragments (many with the same mass) causes difficulty in unambiguously determining the primary photodissociation pathway and the subsequent unimolecular decomposition of the photoproduct. This is illustrated in the study of Saha et al. ${ }^{21}$ where they performed both state selective photodetection of $\mathrm{OH}$ radicals and fluorescence experiments on 2-bromo-2-nitropropane after photodissociation at $193 \mathrm{~nm}$. They speculated that the $\mathrm{OH}$ radicals could arise from several different pathways but were unable to determine which one(s). In addition, their fluorescence data, despite appearing at the wavelengths expected for electronically excited $\mathrm{NO}_{2}$ radicals, ${ }^{20}$ may have included other electronically excited fragments. Our previous experimental study ${ }^{22}$ sought to obtain a complete description of these photolytic pathways by using a crossed laser-molecular beam scattering apparatus and a velocity map imaging apparatus. Although that study identified most, if not all, of the dissociation pathways, the multitude of overlapping signal from different fragments prevented us from achieving unambiguous identification of each channel and their respective properties (i.e., translational energy distributions). These difficulties were caused primarily by the limited detection schemes available at that time: $200 \mathrm{eV}$ electron bombardment on the scattering apparatus and $10.5 \mathrm{eV}$ photoionization on the imaging apparatus. Although this study concentrated on using 2-bromo-2-nitropropane as a model material for the decomposition of TNAZ and FOX-7, some of the assignments of dissociation pathways required further investigation. Because halonitroalkanes have the potential to be excellent precursors for kinetic studies of energetic materials, it is important to possess a detailed understanding of the photolytic pathways.

To obtain such detailed photolytic information, we undertook additional experiments to confirm our identifications in the 2013 study $^{22}$ and further elucidate the photodissociation dynamics of 2-bromo-2-nitropropane. In our new study, presented herein, we detected bromine atoms via state selective REMPI and expanded our detection scheme for other radicals via the use of the crossed-laser molecular beam scattering apparatus at the National Synchrotron Radiation Research Center (NSRRC) in Hsinchu, Taiwan. The NSRRC provided tunable VUV photoionization to separate and distinguish competing dissociation channels in 2-bromo-2-nitropropane. Our new results provide a refinement for the channels seen in the previous study ${ }^{22}$ as well as provide unambiguous identifications for almost all of the dissociation channels available to 2-bromo-2-nitropropane. Though these new results do not alter the major conclusions of our previous study ${ }^{22}$ related to the decomposition of energetic materials, they do give extremely detailed information about the photodissociation of halonitroalkanes, which are important for benchmarking future photolytic experiments and high level electronic structure calculations on such molecules.

\section{EXPERIMENTAL SECTION}

Scattering Apparatus at the National Synchrotron Radiation Research Center (NSRRC). The scattering data presented in this paper were taken at the National Synchrotron Radiation Research Center (NSRRC) in Hsinchu, Taiwan, using the U9 Chemical Dynamics Beamline and a crossed lasermolecular beam scattering apparatus. This apparatus has been described in detail elsewhere, ${ }^{23-25}$ and only a brief description will be given here. A molecular beam is created by seeding 2bromo-2-nitropropane (Aldrich, 97\%) in neon to a total pressure of 600 Torr. The beam is then supersonically expanded through a pulsed nozzle operating at $100 \mathrm{~Hz}$ at a temperature of $\sim 80{ }^{\circ} \mathrm{C}$. The beam was then intersected perpendicularly by unpolarized $193 \mathrm{~nm}$ photons from a LPF 200 Lambda Physik Laser Technik laser. The laser was focused to a $9 \mathrm{~mm}^{2}$ spot, and the power was held at $\sim 4-5 \mathrm{~mJ} /$ pulse. After photodissociation, those fragments possessing the correct net velocity vector (the vector sum of the molecular beam velocity, the velocity imparted by the photodissociation, and the subsequent velocity from the dissociation of the intermediate) travel $10.05 \mathrm{~cm}$ and enter the detector. These fragments were subsequently ionized by tunable VUV photons from the synchrotron; the VUV radiation was passed through a gas cell containing $\sim 10$ Torr of argon, which filtered out the higher harmonics from the synchrotron. After ionization, the fragments are accelerated through a series of ion lenses, mass selected by an Extrel 1.2 MHz quadrupole and detected via a Daly detector. ${ }^{26}$ The signal was binned in $1 \mu$ s intervals of the total (neutral + ion) flight time. The calibrated ion flight constant of $5.43 \mu \mathrm{s} \mathrm{amu} u^{-1 / 2}$ was used to calculate and subtract the ion flight time from all of the TOF spectra presented herein. Therefore, all TOF spectra in this paper show only the neutral flight time of the detected fragments. The molecular beam velocity was characterized by a hole-burning (photodepletion) method. This was performed by acquiring TOF spectra (with the molecular beam on axis) with the pulse nozzle operating at $100 \mathrm{~Hz}$ and the laser at $50 \mathrm{~Hz}$. Subtraction of the "laser-on" signal from the "laser-off" signal gives the velocity characterization for those molecules in the beam that are photodissociated with the laser. All TOF spectra were fit via forward convolution fitting using the CMLAB2 program. ${ }^{27}$ Contribution to the signal from the photodissociation of clusters, producing slowly recoiling 2-bromo-2-nitropropane molecules, was identified by identical and slow velocity distributions at several mass-to-charge ratios, all major peaks in the mass spectrum of 2-bromo-2-nitropropane. We also retook some spectra at photoionization energies below the corresponding appearance energy.

University of Chicago Scattering Apparatus. A second crossed laser-molecular beam scattering apparatus, this one with electron bombardment detection, was used to take a small amount of the data presented in this study. The methodology is described in detail in the previous experimental paper on this system, and only a brief description will be provided here. ${ }^{22}$ Briefly, 2-bromo-2-nitropropane (Aldrich, 97\%) is seeded in helium to a total pressure of 400 Torr and expanded supersonically through a continuous (not pulsed) nozzle $(d=$ 
$0.15 \mathrm{~mm}$ ) heated to $\sim 150{ }^{\circ} \mathrm{C}$. After the beam is collimated via two skimmers, it is intersected perpendicularly by unpolarized $193 \mathrm{~nm}$ photons from a Lumonics PM-848 excimer laser. After photodissociation, those fragments with the correct net velocity vector (the vector sum of the molecular beam velocity, the velocity vector imparted upon photodissociation, and the subsequent velocity from the dissociation of the intermediate) enter the detector region and are subsequently ionized by 200 $\mathrm{eV}$ electron bombardment. ${ }^{28}$ The ionized fragments are then accelerated by a series of ion lenses, mass selected by a quadrupole mass spectrometer and detected via a Daly detector. $^{27}$ The signal is binned in $2 \mu$ s increments of the total flight time (neutral + ion). Using the calibrated ion flight constant of $4.5 \mu \mathrm{s} \mathrm{amu} u^{-1 / 2}$, the ion flight time may be subtracted out of the total flight time, giving only the neutral flight time; all TOF spectra presented herein show only the neutral TOF with the ion flight time subtracted out. The molecular beam velocity was characterized by sending the beam on axis through a chopper wheel spinning at $300 \mathrm{~Hz}$.

Velocity Map Imaging Apparatus. A velocity map imaging apparatus was used to collect supplemental data in this experiment. The apparatus is described in detail elsewhere, and only a brief description will be given here. ${ }^{29-31}$ The molecular beam is created by passing helium through a liquid sample of 2-bromo-2-nitropropane (Aldrich, 97\%) at a total pressure of 500 Torr. The resulting beam was supersonically expanded through a pulsed valve held at $\sim 150{ }^{\circ} \mathrm{C}$ and collimated with a skimmer. The beam is then intersected by a perpendicularly propagating vertically polarized $193 \mathrm{~nm}$ photons from a GAM excimer laser. The laser is focused to a spot of $\sim 1 \mathrm{~mm}^{2}$ with powers of $\sim 0.5 \mathrm{~mJ} /$ pulse. Approximately $40 \mathrm{~ns}$ after interaction, the fragments are ionized by $118 \mathrm{~nm}$ light $(10.5 \mathrm{eV})$, created by tripling the third harmonic of a $\mathrm{Nd}$ :YAG laser through a xenon gas cell. ${ }^{32}$

The ions pass through an electrostatic lens system containing a repeller and extractor plate held in a voltage ratio of 1.4:1. This lens assembly accelerates the fragments down a grounded TOF tube where they impact the detector. The detector consists of a position-sensitive Chevron microchannel plate (MCP) gated with a $-750 \mathrm{~V}$ pulse coinciding with the arrival time of the mass to charge ratio of interest. Upon impact, the MCP released an electron cascade that induces phosphorescence on a phosphor screen directly behind the MCP. A CCD camera records the resulting light.

In addition to the $10.5 \mathrm{eV}$ ionization energy scheme, we employed $2+1$ resonance enhanced multiphoton ionization for detection of atomic bromine. To state selectively ionize both spin-orbit states of bromine, we used $266.60 \mathrm{~nm}\left(5 \mathrm{p}{ }^{4} \mathrm{P}_{3 / 2} \leftarrow\right.$ $\left.4 \mathrm{p}^{2} \mathrm{P}_{3 / 2}\right)$ and $266.67 \mathrm{~nm}\left(5 \mathrm{p}{ }^{4} \mathrm{~S}_{3 / 2} \leftarrow 4 \mathrm{p}^{2} \mathrm{P}_{1 / 2}\right)$. We generated these wavelengths by doubling the output of a Lambda Physik, FL 3002 dye laser (Coumarin 540 dye) pumped by the third harmonic of an Nd:YAG laser (Continuum Powerlite Precision 9020). The wavelength of the fundamental output of the dye laser was measured and reported in vacuum wavelengths by a Coherent WaveMaster meter and correlated with previous REMPI experiments. ${ }^{33-35}$ Acquisition of the images was performed by scanning across the Doppler profile of \pm 0.008 $\mathrm{nm}$.

Computational Methods. All geometries and energies were calculated at the G4//B3LYP/6-311++g(3df,2p) level ${ }^{36}$ using the Gaussian Software Package. ${ }^{37}$

\section{RESULTS AND ANALYSIS}

1. Photodissociation Channels of 2-Bromo-2-nitropropane, $\mathrm{CH}_{3} \mathrm{C}\left(\mathrm{NO}_{2}\right)(\mathrm{Br}) \mathrm{CH}_{3}$. A. Overview. Upon irradiation with $193 \mathrm{~nm}$ photons, 2-bromo-2-nitropropane was shown to undergo four primary photodissociation channels (eqs 1-4): $\mathrm{C}-\mathrm{Br}$ fission to yield 2-nitro-2-propyl radical, $\mathrm{HBr}$ elimination to yield 2-nitropropene, $\mathrm{C}-\mathrm{NO}_{2}$ fission to yield the 2-bromo-2propyl radical, and HONO elimination to yield 2-bromopropene; our new study confirms the occurrence of all four pathways. Specifically, although there was no change in the $\mathrm{NO}_{2}$ photofission and HONO elimination recoil kinetic energy distributions, $P\left(E_{\mathrm{T}}\right)$ 's, the new data show that the $\mathrm{HBr}$ photoelimination and $\mathrm{C}-\mathrm{Br}$ bond fission pathways have significantly different $P\left(E_{\mathrm{T}}\right)$ 's from the previous study. ${ }^{22}$ The new data also identify stable 2-nitropropene fragments arising from primary $\mathrm{HBr}$ elimination.

$$
\begin{aligned}
& \mathrm{CH}_{3} \mathrm{C}\left(\mathrm{NO}_{2}\right)(\mathrm{Br}) \mathrm{CH}_{3}+h v \rightarrow \mathrm{CH}_{3} \mathrm{C}(\mathrm{Br}) \mathrm{CH}_{3}+\mathrm{NO}_{2} \\
& \Delta H_{0 \mathrm{~K}}=54.0 \mathrm{kcal} / \mathrm{mol} \\
& \mathrm{CH}_{3} \mathrm{C}\left(\mathrm{NO}_{2}\right)(\mathrm{Br}) \mathrm{CH}_{3}+h v \\
& \rightarrow \mathrm{CH}_{3} \mathrm{C}(\mathrm{Br})=\mathrm{CH}_{2}+\mathrm{HONO} \\
& \quad \Delta H_{0 \mathrm{~K}}=15.7 \mathrm{kcal} / \mathrm{mol} \\
& \mathrm{CH}_{3} \mathrm{C}\left(\mathrm{NO}_{2}\right)(\mathrm{Br}) \mathrm{CH}_{3}+h v \rightarrow \mathrm{CH}_{3} \mathrm{C}\left(\mathrm{NO}_{2}\right) \mathrm{CH}_{3}+\mathrm{Br} \\
& \quad \Delta H_{0 \mathrm{~K}}=59.2 \mathrm{kcal} / \mathrm{mol} \\
& \mathrm{CH}_{3} \mathrm{C}\left(\mathrm{NO}_{2}\right)(\mathrm{Br}) \mathrm{CH}_{3}+h v \\
& \rightarrow \mathrm{CH}_{3} \mathrm{C}\left(\mathrm{NO}_{2}\right)=\mathrm{CH}_{2}+\mathrm{HBr} \\
& \Delta H_{0 \mathrm{~K}}=15.5 \mathrm{kcal} / \mathrm{mol}
\end{aligned}
$$

B. Primary $\mathrm{C}-\mathrm{NO}_{2}$ Photofission Yielding $\mathrm{NO}_{2}$ and $\mathrm{CH}_{3} \mathrm{C}(\mathrm{Br}) \mathrm{CH}_{3}$. Evidence for this channel is given in the $\mathrm{m} / \mathrm{e}=$ 123 and $m / e=46$ time-of-flight (TOF) spectra shown in Figures 1 and 3, respectively. Our previous study had detected the same signal using velocity map imaging and a photoionization energy of $10.5 \mathrm{eV}$; so the fit shown as a black solid

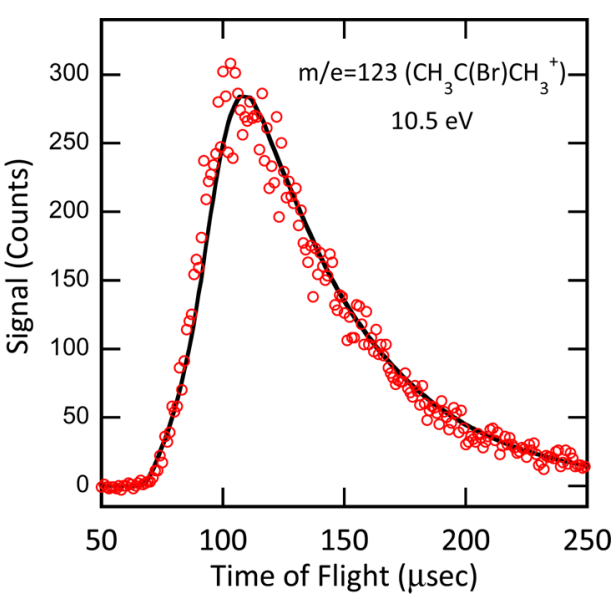

Figure 1. Time-of-flight spectrum taken at $m / e=123, \mathrm{CH}_{3} \mathrm{C}(\mathrm{Br})$ $\mathrm{CH}_{3}{ }^{+}$, at a source angle of $20^{\circ}$ and a photoionization of $10.5 \mathrm{eV}$. Data are shown in red circles. The $\mathrm{CH}_{3} \mathrm{C}(\mathrm{Br}) \mathrm{CH}_{3}$ products from primary $\mathrm{C}-\mathrm{NO}_{2}$ photofission are fit by the black line using the red $P\left(E_{\mathrm{T}}\right)$ shown in Figure 2. 


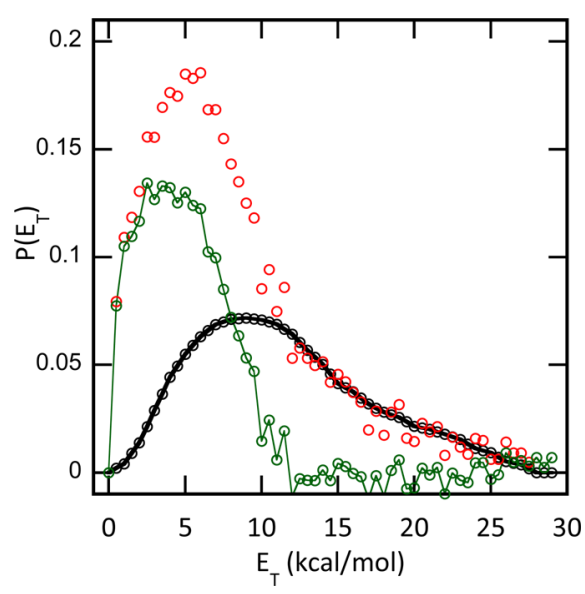

Figure 2. Photofragment recoil kinetic energy distribution for $\mathrm{C}-\mathrm{NO}_{2}$ fission (eq 1) in 2-bromo-2-nitropropane at $193 \mathrm{~nm}$. Forward convolution of the entirety of the signal at $m / e=123\left(\mathrm{CH}_{3} \mathrm{C}(\mathrm{Br})\right.$ $\left.\mathrm{CH}_{3}{ }^{+}\right)$in Figure 1 gives the total $P\left(E_{\mathrm{T}}\right)$ shown in red circles. The partial $P\left(E_{\mathrm{T}}\right)$ shown in black circles was derived from forward convolution fitting of the signal arriving between 130 and $200 \mu \mathrm{s}$ in the $m / e=46\left(\mathrm{NO}_{2}{ }^{+}\right)$TOF taken in Chicago at $200 \mathrm{eV}$ ionization energy (Figure 3: upper frame); this signal represents the $\mathrm{NO}_{2}$ photofragments detected at parent ion that were not lost to secondary photodissociation (section $5 \mathrm{~B}$ ). The remaining portion of the $P\left(E_{\mathrm{T}}\right)$, shown in green, results in $\mathrm{NO}_{2}$ fragments that are subject to these secondary dissociation processes; about half survive secondary photodissociation and are detected at $\mathrm{NO}_{2}{ }^{+}$in the lower frame of Figure 3 because they are not dissociatively ionized to $\mathrm{NO}^{+}$upon $10.84 \mathrm{eV}$ photoionization..

line in Figure 1 is calculated from the primary $P\left(E_{\mathrm{T}}\right)$ derived from that imaging data. The primary $P\left(E_{\mathrm{T}}\right)$ for $\mathrm{C}-\mathrm{NO}_{2}$ photofission, shown in open red circles in Figure 2, gives a good fit to the current $m / e=123\left(\mathrm{CH}_{3} \mathrm{C}(\mathrm{Br}) \mathrm{CH}_{3}{ }^{+}\right)$data from the NSRRC (Figure 1). Forward convolution fitting using the total (red) $P\left(E_{\mathrm{T}}\right)$ shown in Figure 2 gives the black line fit on the $m / e=123$ TOF spectrum (this $P\left(E_{\mathrm{T}}\right)$ was previously derived in ref 22). In the previous study, however, the $m / e=46$ TOF spectrum only included the fast $\mathrm{NO}_{2}$ arising from this channel (Figure 3, upper frame). Forward convolution fitting using the black $P\left(E_{\mathrm{T}}\right)$ (derived from the $m / e=46$ TOF spectrum in Chicago) in Figure 2 gives the signal shown in the NSRRC $m / e=46$ TOF spectrum in the lower frame of Figure 3. Though this $P\left(E_{\mathrm{T}}\right)$ clearly fits on the fast edge of the new data, there are significantly more slow $\mathrm{NO}_{2}$ fragments than were observed in the previous experiment using electron bombardment ionization. This suggests that not all of the $\mathrm{NO}_{2}$ fragments formed with the green line $P\left(E_{\mathrm{T}}\right)$ shown in Figure 2 (derived by subtraction of the open red circles and the black line) undergo secondary dissociation as was postulated in the previous study. Although the entirety of the fast kinetic energy $\mathrm{NO}_{2}$ fragments (black line $P\left(E_{\mathrm{T}}\right)$ ) are stable and appear at $m / e$ $=46\left(\mathrm{NO}_{2}^{+}\right)$, only a fraction of the slower $\mathrm{NO}_{2}$ fragments appear at $\mathrm{NO}_{2}{ }^{+}$. The fraction that does undergo secondary dissociation is determined by comparing the integrated areas of the $P\left(E_{\mathrm{T}}\right)$ 's shown in black and green derived from $m / e=46$ $\left(\mathrm{NO}_{2}{ }^{+}\right)$and those from $m / e=123\left(\mathrm{CH}_{3} \mathrm{C}(\mathrm{Br}) \mathrm{CH}_{3}{ }^{+}\right)$. Using this method, $\sim 52 \%$ of the $\mathrm{NO}_{2}$ fragments formed with slow kinetic energies undergo secondary dissociation events.

The lack of signal arising from the low kinetic $\mathrm{NO}_{2}$ fragments in our previous study is attributed to daughter ionization arising from the higher ionization energy in the Chicago apparatus

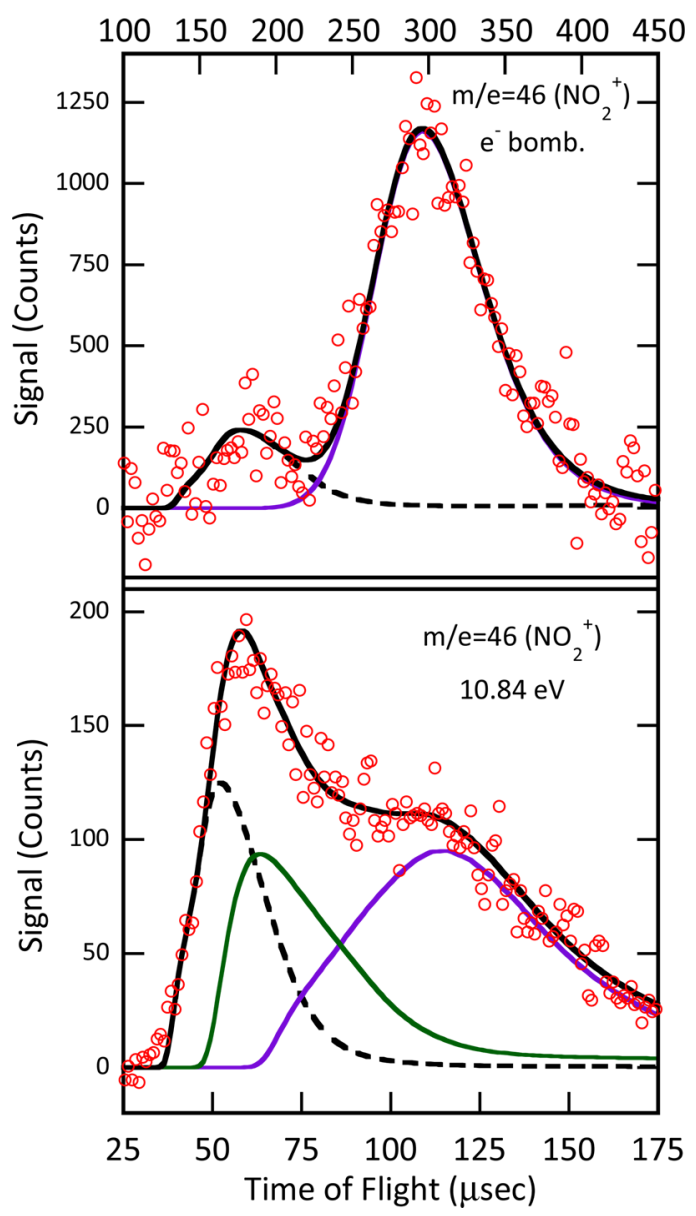

Figure 3. Time-of-flight spectrum taken at $m / e=46, \mathrm{NO}_{2}{ }^{+}$, using two different methods of detection. Upper frame: acquired at a source angle of $10^{\circ}$ using electron bombardment ionization of $200 \mathrm{eV}$. The $\mathrm{NO}_{2}$ fragments that do not undergo secondary dissociation and are detected at parent ion are given by the black dashed line fit calculated from the $P\left(E_{\mathrm{T}}\right)$ shown in black circles in Figure 2. The contribution shown in purple line is from the dissociation of molecular clusters in the beam. This frame is adapted from ref 22. NOTE: The time-offlight axis is above the upper frame. Lower frame: acquired at a source angle of $10^{\circ}$ and a photoionization energy of $10.84 \mathrm{eV}$. Data are shown in red circles. The remaining $\mathrm{NO}_{2}$ product from $\mathrm{C}-\mathrm{NO}_{2}$ photofission (eq 1) is fit by a dashed black line using the partial $P\left(E_{\mathrm{T}}\right)$ shown in black circles in Figure 2. The green line represents the fraction of $\mathrm{NO}_{2}$ products capable of possessing enough vibrational energy to undergo secondary dissociation, but these products still appear in the lower $\mathrm{m} /$ $\mathrm{e}=46\left(\mathrm{NO}_{2}^{+}\right)$TOF spectrum; this fit is derived using the $P\left(E_{\mathrm{T}}\right)$ shown as green circles in Figure 2 with the probability reduced by a factor of 2 (as some $\mathrm{NO}_{2}$ products are photodissociated). The fit shown as the purple solid line represents the contribution from clusters in the molecular beam.

(200 eV electron bombardment vs $10.84 \mathrm{eV}$ photoionization). The $\mathrm{NO}_{2}$ that does not appear at $\mathrm{NO}_{2}{ }^{+}$undergoes either unimolecular dissociation to $\mathrm{NO}$ (mass 30$)+\mathrm{O}$ (mass 16) or a second photodissociation to $\mathrm{NO}+\mathrm{O}$; these fits are shown in the Supporting Information and in section $5 \mathrm{~B}$, respectively.

C. Primary HONO Elimination Yielding HONO and $\mathrm{CH}_{3} \mathrm{C}(\mathrm{Br})=\mathrm{CH}_{2}$. The HONO photoelimination channel is confirmed by signal at $m / e=122\left(\mathrm{CH}_{3} \mathrm{C}(\mathrm{Br})=\mathrm{CH}_{2}^{+}\right)(\mathrm{TOF}$ spectrum shown in Figure 4). The detected 2-bromopropene fragments could arise from two alternative dissociation channels: secondary $\mathrm{H}$-loss from $\mathrm{CH}_{3} \mathrm{C}(\mathrm{Br}) \mathrm{CH}_{3}$ or dissociative ionization of $\mathrm{CH}_{3} \mathrm{C}(\mathrm{Br}) \mathrm{CH}_{3}$ to $\mathrm{CH}_{3} \mathrm{C}(\mathrm{Br}) \mathrm{CH}_{2}^{+}$via a hydrogen 


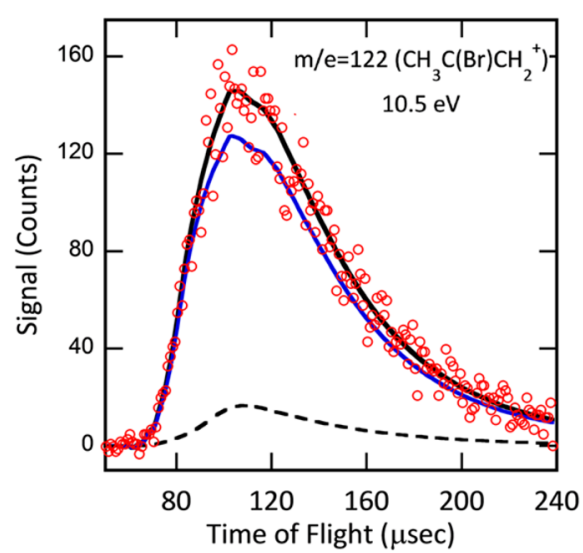

Figure 4. Time-of-flight spectrum taken at $m / e=122, \mathrm{CH}_{3} \mathrm{C}(\mathrm{Br})=$ $\mathrm{CH}_{2}{ }^{+}$, at a source angle of $20^{\circ}$ and a photoionization energy of 10.5 eV. Data are shown in red circles. The $\mathrm{CH}_{3} \mathrm{C}(\mathrm{Br})=\mathrm{CH}_{2}$ products from primary $\mathrm{HONO}$ elimination are fit by the solid blue line using the entirety of the $P\left(E_{\mathrm{T}}\right)$ shown in (ref 22, Figure 5). The contribution from the secondary $\mathrm{H}$-loss from the $\mathrm{CH}_{3} \mathrm{C}(\mathrm{Br}) \mathrm{CH}_{3}$ fragments (primary $\mathrm{C}-\mathrm{NO}_{2}$ photofission) is shown as the dashed black line and is fit using the primary $\mathrm{C}-\mathrm{NO}_{2} P\left(E_{\mathrm{T}}\right)$ shown in Figure 2.

atom loss; the calculated appearance energy $(\mathrm{AE})$ of $\mathrm{CH}_{3} \mathrm{C}$ $(\mathrm{Br})=\mathrm{CH}_{2}{ }^{+}$from $\mathrm{CH}_{3} \mathrm{C}(\mathrm{Br}) \mathrm{CH}_{3}$ is $11.27 \mathrm{eV}$. Because this $\mathrm{AE}$ is above the photoionization energy used, it is assumed not to occur. If the signal at $m / e=122$ was entirely due to the secondary H-loss channel, then the $m / e=122$ TOF spectrum would be well fit using only the primary $\mathrm{C}-\mathrm{NO}_{2} P\left(E_{\mathrm{T}}\right)$ shown as open red circles in Figure 2; this is because the $\mathrm{H}$ atom is not sufficiently massive to affect the velocity of the resulting $\mathrm{CH}_{3} \mathrm{C}(\mathrm{Br}) \mathrm{CH}_{2}$ fragment. Forward convolution fitting using the entirety of the primary $\mathrm{C}-\mathrm{NO}_{2} P\left(E_{\mathrm{T}}\right)$ gives the black line fit on the $m / e=122$ TOF spectrum (shown in Supporting Information as Figure S1). Although this channel is presumed to occur due to the low reaction barrier of $37.1 \mathrm{kcal} / \mathrm{mol}$, it clearly does not encompass the entirety of the $m / e=122$ TOF spectrum because it is unable to produce $m / e=122$ fragments with sufficient kinetic energies to fit the fast edge of the TOF spectrum. Because this situation is identical to our previous study, ${ }^{22}$ we assume that the primary HONO photoelimination derived in that study via the velocity map imaging data is correct. In that study, we attributed a small amount of the $m / e$ $=122$ signal to the $\mathrm{H}$-loss channel from $\mathrm{CH}_{3} \mathrm{C}(\mathrm{Br}) \mathrm{CH}_{3}$ fragments; this contribution is shown as the dashed black line in the $m / e=122$ TOF spectrum and derived with the primary $\mathrm{C}-\mathrm{NO}_{2}$ photofission $P\left(E_{\mathrm{T}}\right)$ shown in Figure 2. Forward convolution fitting using the $P\left(E_{\mathrm{T}}\right)$ derived from the Chicago imaging data (ref 22, Figure 4) gives the blue solid line fit in the $m / e=122$ TOF spectrum; this predicted signal fits the remainder of the $m / e=122$ TOF spectrum (that which is attributed to primary HONO loss). As demonstrated previously, the cofragment in this pathway (HONO) undergoes unimolecular dissociation to $\mathrm{OH}$ (mass 17) + NO (mass 30) and this channel is fit later in the report (section $4 \mathrm{~B}$ ).

D. Primary $\mathrm{C}-\mathrm{Br}$ Bond Photofission Yielding $\mathrm{Br}$ and $\mathrm{CH}_{3} \mathrm{C}\left(\mathrm{NO}_{2}\right) \mathrm{CH}_{3}$. One of the major photodissociation channels at $193 \mathrm{~nm}$ for brominated hydrocarbons is $\mathrm{C}-\mathrm{Br}$ bond fission via a repulsive $\mathrm{n} \rightarrow \sigma^{*}$ transition. Although our previous study identified this process as a major channel for 2-bromo-2nitropropane, the dissociative ionization of $\mathrm{HBr}$ gives signal at $m / e=79\left(\mathrm{Br}^{+}\right)$, making accurate identification of the $P\left(E_{\mathrm{T}}\right)$ for this channel difficult. It was assumed that the $\mathrm{C}-\mathrm{Br}$ photofission would resemble a "standard" repulsive dissociation event comprising a fast and narrow distribution of translational energies. In our new study, we sought to test this assumption by acquiring the $m / e=79\left(\mathrm{Br}^{+}\right)$signal, which includes only the contribution from neutral bromine atoms. To this end, we acquired $m / e=79\left(\mathrm{Br}^{+}\right)$TOF spectra at a low photoionization energy $(11.71 \mathrm{eV})$ to avoid any signal arising from dissociative ionization of $\mathrm{HBr}$; this TOF spectrum is shown in Figure 5.

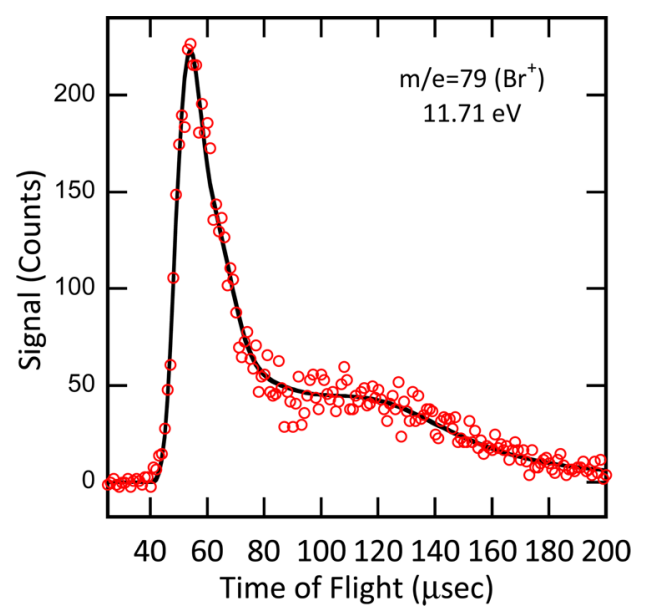

Figure 5. Time-of-flight spectrum taken at $m / e=79, \mathrm{Br}^{+}$, at a source angle of $20^{\circ}$ and a photoionization energy of $11.71 \mathrm{eV}$. Data are shown in red circles. The $\mathrm{Br}$ products from primary $\mathrm{C}-\mathrm{Br}$ photofission are fit by the black line using the entirety of the $P\left(E_{\mathrm{T}}\right)$ shown in Figure 6 .

Interestingly, this signal is bimodal with a fast sharp peak and a broader slow peak. Forward convolution fitting of the entirety of the signal in Figure 5 gives the $P\left(E_{\mathrm{T}}\right)$ shown in Figure 6. Forward convolution fitting using the $P\left(E_{\mathrm{T}}\right)$ in Figure 6 also clearly fits the $m / e=79$ TOF spectrum taken in Chicago (Figure S2, Supporting Information). The $P\left(E_{\mathrm{T}}\right)$ is trimodal and ranges from 0 to $40 \mathrm{kcal} / \mathrm{mol}$. Because this $P\left(E_{\mathrm{T}}\right)$ does not

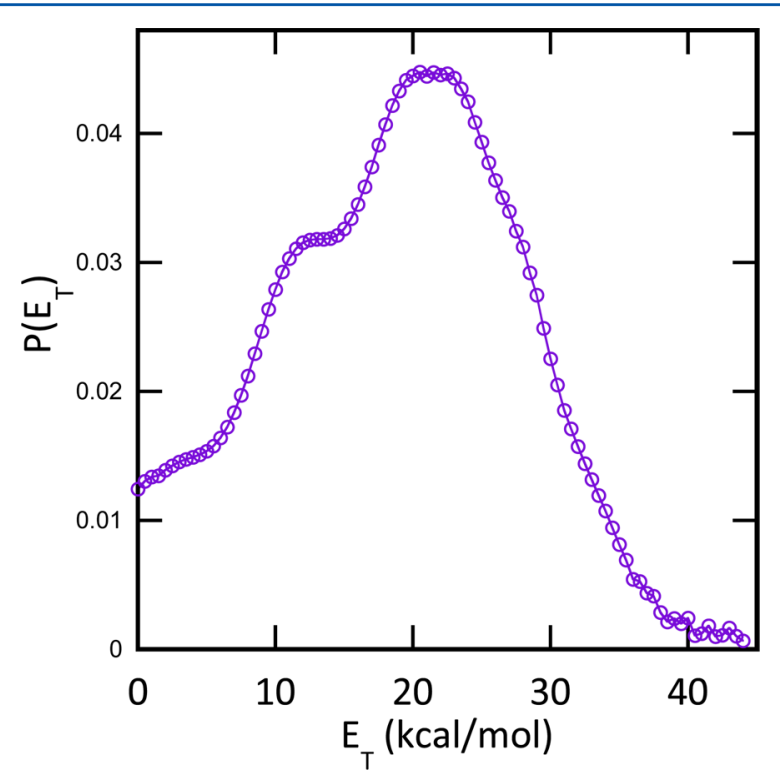

Figure 6. Photofragment recoil kinetic energy distribution for $\mathrm{C}-\mathrm{Br}$ fission (eq 3) in 2-bromo-2-nitropropane at $193 \mathrm{~nm}$. The $P\left(E_{\mathrm{T}}\right)$ is derived from the forward convolution fit of the entire signal shown as red circles in Figure 5. 
resemble any "standard" $\mathrm{C}-\mathrm{Br}$ photofission $P\left(E_{\mathrm{T}}\right)$ 's for brominated hydrocarbons, we took velocity map images of the $\mathrm{Br}$ atoms to confirm the $P\left(E_{\mathrm{T}}\right)$. Using REMPI, we acquired velocity map images of bromine atoms in both spin-orbit states $\left({ }^{2} \mathrm{P}_{3 / 2}\right.$ and $\left.{ }^{2} \mathrm{P}_{1 / 2}\right)$. The $\operatorname{Br}\left({ }^{2} \mathrm{P}_{3 / 2}\right)$ and $\mathrm{Br} *\left({ }^{2} \mathrm{P}_{1 / 2}\right) P\left(E_{\mathrm{T}}\right)$ 's are shown in Figure 7 . Interestingly, both $P\left(E_{\mathrm{T}}\right)$ 's show

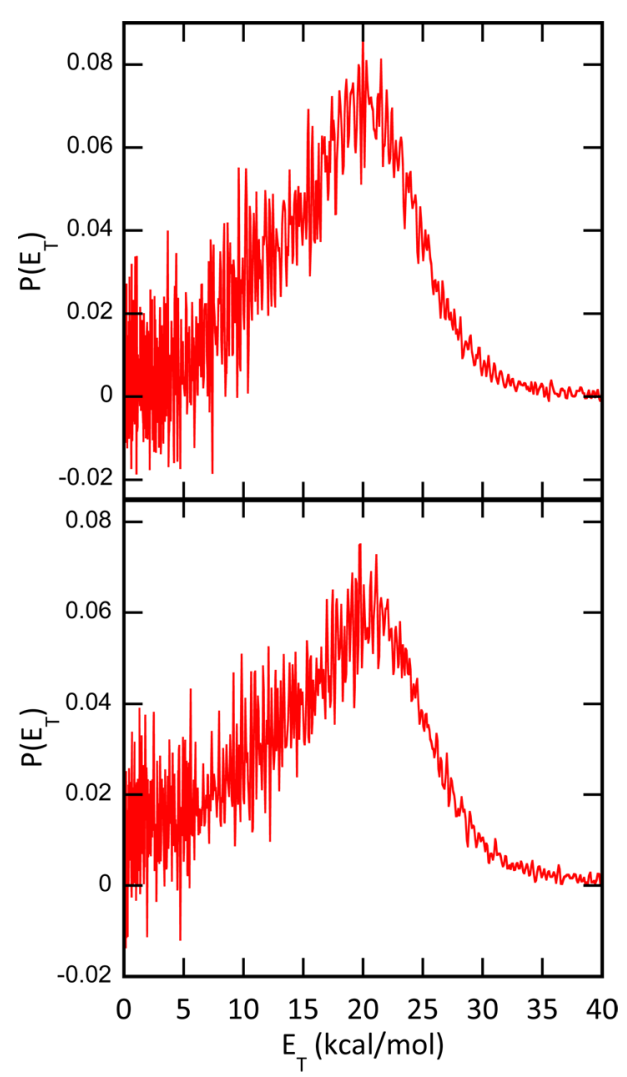

Figure 7. Photofragment recoil kinetic energy distribution for $\mathrm{C}-\mathrm{Br}$ fission (eq 3) in 2-bromo-2-nitropropane at $193 \mathrm{~nm}$. These $P\left(E_{\mathrm{T}}\right)$ were obtained via state selective REMPI ionization of the bromine fragments. The top frame represents $\operatorname{Br}\left({ }^{2} \mathrm{P}_{3 / 2}\right)$ and the bottom $\operatorname{Br}\left({ }^{2} \mathrm{P}_{1 / 2}\right)$.

trimodality nearly identical to that of the total $P\left(E_{\mathrm{T}}\right)$ derived from the NSRRC $m / e=79$ TOF spectrum. Note that the trimodal $P\left(E_{\mathrm{T}}\right)$ suggest that there are three mechanisms occurring during $\mathrm{C}-\mathrm{Br}$ photofission and it is likely that the $\mathrm{CH}_{3} \mathrm{C}\left(\mathrm{NO}_{2}\right) \mathrm{CH}_{3}$ cofragment is formed in three different electronic states. Because all three peaks appear in both spin states of bromine, it is unlikely that any of the $\mathrm{Br}$ atoms are arising from a unimolecular dissociation of a vibrationally excited cofragment formed in the HONO photoelimination or $\mathrm{C}-\mathrm{NO}_{2}$ photofission; such unimolecular dissociations would form products in only the ${ }^{2} \mathrm{P}_{3 / 2}$ state due to the $10.5 \mathrm{kcal} / \mathrm{mol}$ energy difference between the two spin-orbit states. The $\mathrm{C}-\mathrm{Br}$ $P\left(E_{\mathrm{T}}\right)$ derived from the NSRRC TOF spectra (Figure 5) was used to fit all subsequent secondary unimolecular dissociation events presented in section 2; so we did not need to determine a branching ratio between the $\operatorname{Br}\left({ }^{2} \mathrm{P}_{3 / 2}\right)$ and $\mathrm{Br} *\left({ }^{2} \mathrm{P}_{1 / 2}\right)$ channels. Note that the imaging data do not show signal at an $E_{\mathrm{T}}$ of approximately $31 \mathrm{kcal} / \mathrm{mol}$; so the signal in this range seen in the $11.71 \mathrm{eV}$ TOF spectrum in Figure 5 may result from a two-photon dissociation.

E. $\mathrm{HBr}$ Elimination Yielding $\mathrm{HBr}$ and $\mathrm{CH}_{3} \mathrm{C}\left(\mathrm{NO}_{2}\right)=\mathrm{CH}_{2}$. The TOF signal at $m / e=82\left(\mathrm{HBr}^{+}\right)$evidences the $\mathrm{HBr}$ photoelimination channel (Figure 8); forward convolution fitting using the total (blue solid) $P\left(E_{\mathrm{T}}\right)$ shown in Figure 9,

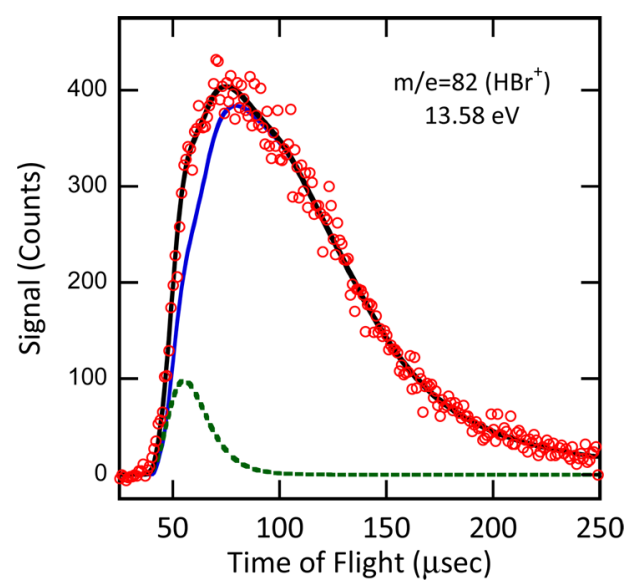

Figure 8. Time-of-flight spectrum taken at $m / e=82, \mathrm{H}^{81} \mathrm{Br}^{+}$, at a source angle of $10^{\circ}$ and a photoionization energy of $13.58 \mathrm{eV}$. Data are shown in red circles. The $\mathrm{HBr}$ products from $\mathrm{HBr}$ photoelimination (eq 4) are fit by the blue line and is used to derive the $\mathrm{HBr}$ photoelimination $P\left(E_{\mathrm{T}}\right)$ shown in Figure 9. The $\mathrm{HBr}$ fragments arising from secondary $\mathrm{HBr}$ loss from vibrationally excited $\mathrm{CH}_{3} \mathrm{C}(\mathrm{Br})=\mathrm{CH}_{2}$ species (section 5C) are shown as the dashed green fit calculated from the primary HONO $P\left(E_{\mathrm{T}}\right)$ and the secondary $P\left(E_{\mathrm{T}}\right)$ for $\mathrm{HBr}$ elimination from $\mathrm{CH}_{3} \mathrm{C}(\mathrm{Br}) \mathrm{CH}_{2}$ shown in Figure $\mathrm{S} 16$ (Supporting Information).

gives the blue solid line fit seen on the $m / e=82$ TOF spectrum (Figure 8$)$. Although this $P\left(E_{\mathrm{T}}\right)$ gives a good fit on the NSRRC data, we used this same $P\left(E_{\mathrm{T}}\right)$ to fit the $m / e=80 \mathrm{TOF}$ spectrum taken in Chicago, which is shown in Figure S4 of the

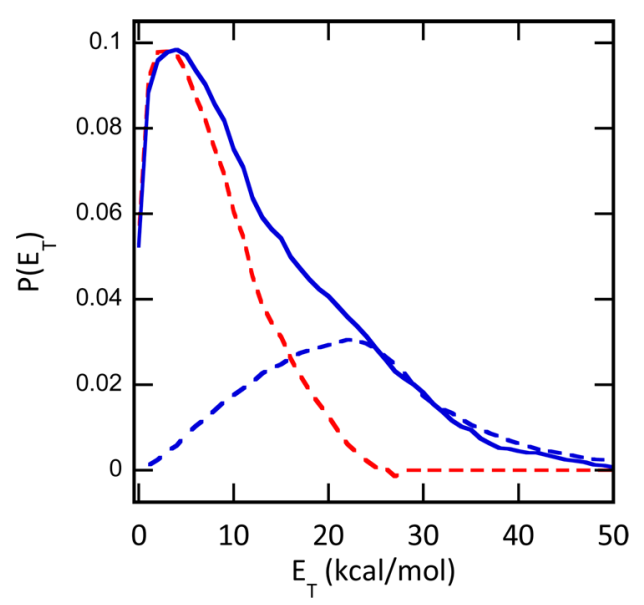

Figure 9. Photofragment recoil kinetic energy distribution for $\mathrm{HBr}$ photoelimination (eq 4) in 2-bromo-2-nitropropane at $193 \mathrm{~nm}$. The total $P\left(E_{\mathrm{T}}\right)$ (blue solid line) is derived from the forward convolution fit shown as the solid blue line in the time-of-flight spectrum taken at $m / e=82\left(\mathrm{HBr}^{+}\right)$shown in Figure 8, the signal assigned to the $\mathrm{HBr}$ primary photoproduct. The $P\left(E_{\mathrm{T}}\right)$ shown as the dashed blue line represents the stable $\mathrm{CH}_{3} \mathrm{C}\left(\mathrm{NO}_{2}\right) \mathrm{CH}_{2}^{+}$fragments arising from primary $\mathrm{HBr}$ photoelimination; this is derived via forward convolution of the dashed blue line fit shown in the $m / e=41\left(\mathrm{CH}_{3} \mathrm{CCH}_{2}{ }^{+}\right)$TOF taken at high ionization energy (Figure 10, bottom frame). The red $P\left(E_{\mathrm{T}}\right)$ represents the unstable $\mathrm{CH}_{3} \mathrm{C}\left(\mathrm{NO}_{2}\right) \mathrm{CH}_{2}$ fragments which undergo subsequent unimolecular dissociation pathways described in section 3 in the text. 
Supporting Information. The $P\left(E_{\mathrm{T}}\right)$ derived from the NSRRC is significantly different from that derived from Chicago data; a comparison is shown in Figure S3 of the Supporting Information. In the low $\mathrm{S}: \mathrm{N}$ data, we attributed a large portion of the fast velocity $\mathrm{HBr}^{+}$signal to $\mathrm{HBr}$ arising from the dissociation of vibrationally excited $\mathrm{CH}_{3} \mathrm{C}(\mathrm{Br}) \mathrm{CH}_{2}$ molecules (dashed green line in Figure 8). With the new data, we can confirm the secondary $P\left(E_{\mathrm{T}}\right)$ for the secondary $\mathrm{HBr}$ loss from vibrationally excited 2-bromopropene with its momentum matched cofragment $\mathrm{C}_{3} \mathrm{H}_{4}$; this allows for derivation of the primary $\mathrm{HBr}$ photoelimination $P\left(E_{\mathrm{T}}\right)$ with much greater accuracy than was available in the previous study. ${ }^{22}$

Interestingly, the NSRRC data provide evidence for 2nitropropene fragments arising from this channel that are stable to further dissociation. This is only possible if the $\mathrm{HBr}$ fragments are formed with more than $\sim 60 \mathrm{kcal} / \mathrm{mol}$ of internal energy. The portion of the $\mathrm{HBr}$ photoelimination $P\left(E_{\mathrm{T}}\right)$ that gives stable 2-nitropropene fragments is shown as the dashed blue $P\left(E_{\mathrm{T}}\right)$ in Figure 9. Evidence for these fragments is given in their dissociative ionization to $m / e=41\left(\mathrm{CH}_{3} \mathrm{CCH}_{2}^{+}\right)$, detected in the ionization energy dependent signal in the $m / e$ $=41$ TOF spectra (Figure 10, top and bottom frame). When we tune the photoionization energy above the calculated $\mathrm{AE}$ of the formation of $m / e=41$ from 2-nitropropene, we see the signal fit in the dashed blue line in Figure 10, lower frame. Forward convolution fitting using the stable (dashed blue) $P\left(E_{\mathrm{T}}\right)$ in Figure 9 gives the dashed blue line fit in the high IE $m / e=41$ TOF spectrum (Figure 10, lower frame); this $P\left(E_{\mathrm{T}}\right)$ also gives the dashed blue line fit in the Chicago $m / e=41$ TOF spectrum (taken at $200 \mathrm{eV}$ ) shown in Figure S5, Supporting Information. Subtraction of the $P\left(E_{\mathrm{T}}\right)$ for the stable 2nitropropene portion (dashed blue line in Figure 9) from the total $P\left(E_{\mathrm{T}}\right)$ (solid blue line in Figure 9) gives the $P\left(E_{\mathrm{T}}\right)$ for the 2-nitropropene products that undergo secondary dissociations. Coincidentally, the $P\left(E_{\mathrm{T}}\right)$ for the unstable 2-nitropropene fragments resembles the primary $\operatorname{HBr} P\left(E_{\mathrm{T}}\right)$ derived previously. This leads to only small changes in the corresponding secondary dissociation $P\left(E_{\mathrm{T}}\right)$ distributions.

F. Branching Ratio between $\mathrm{C}-\mathrm{Br}$ fission and $\mathrm{HBr}$ Elimination. The branching ratio between these two channels can be calculated using the same method as described previously $^{22}$ but using the new $P\left(E_{\mathrm{T}}\right)$ s and fitting parameters used in the current study. To acquire the branching ratio between these two channels, we used the relative amount of signal from each channel in the $m / e=79\left(\mathrm{Br}^{+}\right)$TOF spectrum; the equation used to determine the branching ratio in this fashion is shown in eq 5 .

$$
\frac{\Phi_{\mathrm{Br}}}{\Phi_{\mathrm{HBr}}}=\left(\frac{R_{\text {prob }}(\mathrm{C}-\mathrm{Br})}{R_{\text {prob }}(\mathrm{HBr})}\right)\left(\frac{\sigma_{\text {tot }, \mathrm{HBr}}}{\sigma_{\mathrm{tot}, \mathrm{Br}}}\right)\left(\frac{f^{\mathrm{Br}+/ \mathrm{HBr}}}{f^{\mathrm{Br}{ }^{+} / \mathrm{Br}}}\right)
$$

In eq 5 , the $R_{\text {prob }}$ factor represents the likelihood of a particular channel's occurrence assuming equal ionization cross sections but correcting for kinematic effects and the ionization probability's dependence on residence time in the ionizer; this parameter was derived during our data fitting process. The $\sigma$ term represents the electron bombardment ionization cross section and is experimentally determined for $\mathrm{Br}$ in ref 38 and calculated for $\mathrm{HBr}$ in ref 39. Because a significant portion of $\mathrm{Br}$ appears at $\mathrm{Br}^{2+}$, the total cross section determined in ref 38 is scaled by $3.2 / 3.9$ to determine the cross section for $\mathrm{Br}^{+}$only. The " $f$ " value represents the fraction of ionized molecules which appear at the $m / e$ of interest (in this case $m / e=79$ ).

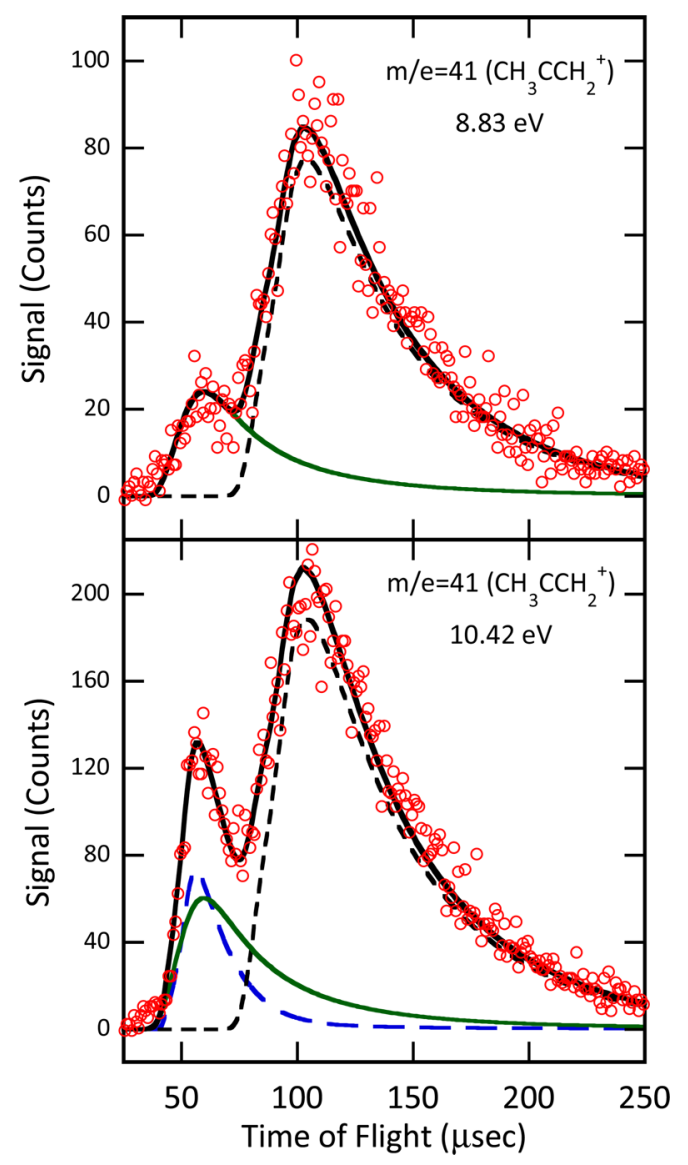

Figure 10. Time-of-flight spectrum taken at $m / e=41, \mathrm{CH}_{3} \mathrm{CCH}_{2}{ }^{+}$, at a source angle of $20^{\circ}$. Top frame: acquired at a photoionzation energy of $8.83 \mathrm{eV}$. Bottom frame: acquired at a photoionzation energy of $10.42 \mathrm{eV}$. Data are shown in red circles. The green fit shows the contribution from $\mathrm{CH}_{3} \mathrm{CCH}_{2}$ products from the dissociation of the 2nitro-2-propyl radical to $\mathrm{HONO}+\mathrm{CH}_{3} \mathrm{CCH}_{2}$ (eq 8); the fit is calculated using the primary $\mathrm{C}-\mathrm{Br}$ photofission $P\left(E_{\mathrm{T}}\right)$ and the $P\left(E_{\mathrm{T}}, 2^{\circ}\right)$ for the dissociation of 2-nitro-2-propyl radicals to $\mathrm{HONO}+$ $\mathrm{CH}_{3} \mathrm{CCH}_{2}$ in Figure 16. The signal peaking near $60 \mu \mathrm{s}$, fit by the dashed blue line, is assigned to the stable $\mathrm{CH}_{3} \mathrm{C}\left(\mathrm{NO}_{2}\right) \mathrm{CH}_{2}$ products arising from primary $\mathrm{HBr}$ elimination and is determined by the dashed blue $P\left(E_{\mathrm{T}}\right)$ in Figure 9. The slowest signal $(>110 \mu \mathrm{s})$ is assigned to dissociative ionization of stable $\mathrm{CH}_{3} \mathrm{C}(\mathrm{Br}) \mathrm{CH}_{3}$ radicals from primary $\mathrm{NO}_{2}$ loss (dashed black fit) and is described fully in the Supporting Information.

Because we have signal at $m / e=80\left(\mathrm{HBr}^{+}\right)$and $m / e=79$ $\left(\mathrm{Br}^{+}\right)$, and know the relative amount of signal arising from $\mathrm{HBr}$ fragments at each, we can determine this ratio experimentally. With our data, the $f\left(\mathrm{Br}^{+} / \mathrm{HBr}\right)$ is determined to be 1.32:1. This value is significantly larger than the value derived via mass spectroscopy in ref 40 of $0.6: 1$. This discrepancy is most likely due to the presence of extremely vibrationally excited $\mathrm{HBr}$ photofragments in our data. Substituting these values into eq 5 gives eq 6 , and the calculated branching ratio is $6.7: 1$.

$$
\frac{\Phi_{\mathrm{Br}}}{\Phi_{\mathrm{HBr}}}=\left(\frac{0.890}{0.085}\right)\left(\frac{3.30 \AA 2}{3.56 \AA^{2}}\right)\left(\frac{1.32 / 2.32}{3.2 / 3.9}\right)=6.7
$$

This contrasts with our previously determined branching ratio of $3: 1$, but the new branching ratio has less error associated with it because the $P\left(E_{\mathrm{T}}\right)$ (those used to derive the fitting parameters) are known with more certainty than in the previous study. ${ }^{22}$ 


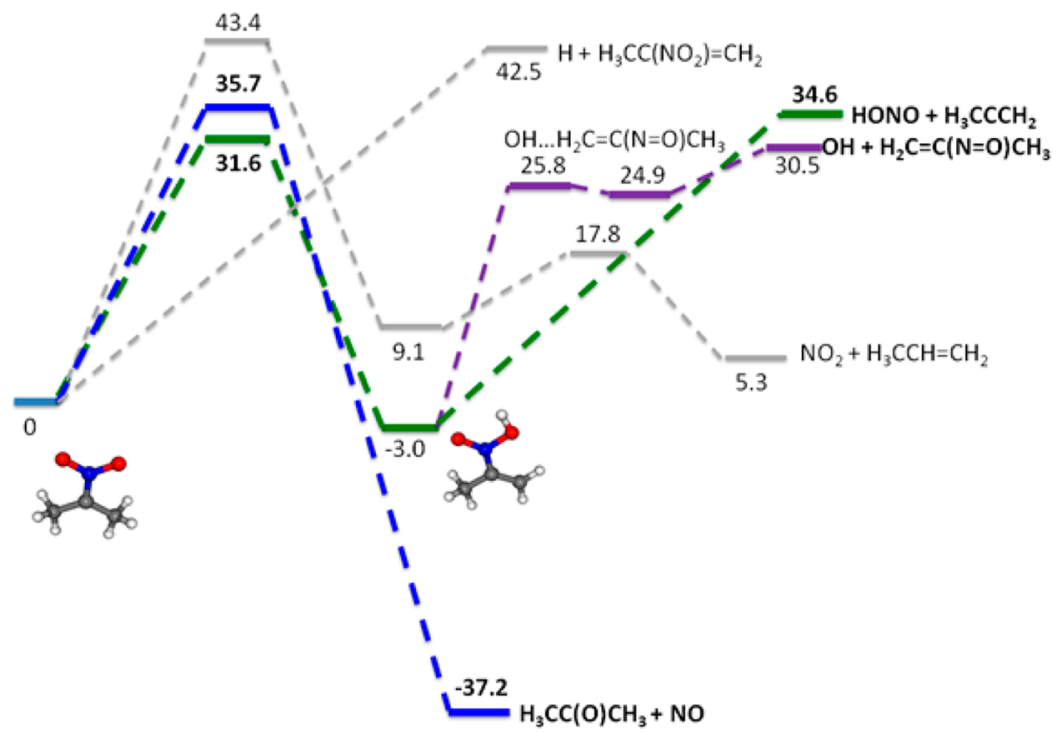

Figure 11. Calculated minima and transition states for the possible dissociation channels of the 2-nitro-2-propyl radical $\left(\mathrm{CH}_{3} \mathrm{C}\left(\mathrm{NO}_{2}\right) \mathrm{CH}_{3}\right)$ on the ground state potential energy surface. All values are expressed in units of $\mathrm{kcal} / \mathrm{mol}$ and were calculated at the G4//B3LYP/6-311++g(3df,2p) level. Bolder lines represent experimentally observed channels. This figure is adapted from ref 22.

\section{Dissociation of Vibrationally Excited $\mathrm{CH}_{3} \mathrm{C}\left(\mathrm{NO}_{2}\right) \mathrm{CH}_{3}$} Resulting from Primary $\mathrm{C}-\mathrm{Br}$ Fission. A. Overview. Photofission of the $\mathrm{C}-\mathrm{Br}$ bond yields vibrationally excited 2nitro-2-propyl radicals, which undergo three subsequent dissociations: loss of $\mathrm{OH}$, loss of $\mathrm{HONO}$, and loss of NO. The data in this study show only modest changes in the $P\left(E_{\mathrm{T}}\right)$ of the HONO loss channel and in the angular distributions of the NO loss pathway. In the case of HONO, the secondary $P\left(E_{\mathrm{T}}\right)$ is slightly slower than was predicted previously, and the NO loss secondary angular distribution is broader with increased intensity at the end points $\left(0^{\circ}\right.$ and $\left.180^{\circ}\right)$. Although the $\mathrm{OH}$ channel was only speculated to occur in the previous study (no data were obtained to prove it), the new data show a strong signal arising from the dissociation of 2-nitro-2-propyl radicals to $\mathrm{OH}+\mathrm{CH}_{3} \mathrm{C}(\mathrm{N}=\mathrm{O}) \mathrm{CH}_{2}$ at $m / e=71\left(\mathrm{CH}_{2} \mathrm{C}(\mathrm{N}=\right.$ $\left.\mathrm{O}) \mathrm{CH}_{3}^{+}\right)$. Figure 11 summarizes the dissociation channels of the 2-nitro-2-propyl radical identified in this study. It shows the calculated barriers for all dissociation channels, indicating the major dissociation channels in bold color lines and the product channels that did not compete effectively in light gray.

B. Dissociation of the $\mathrm{CH}_{3} \mathrm{C}\left(\mathrm{NO}_{2}\right) \mathrm{CH}_{3}$ Radical to $\mathrm{OH}+$ $\mathrm{CH}_{2} \mathrm{C}(\mathrm{N}=\mathrm{O}) \mathrm{CH}_{3}$. The lowest energy dissociation pathway for the nascent 2-nitro-2-propyl radicals is an $\mathrm{H}$-shift from carbon to oxygen followed by $\mathrm{O}-\mathrm{N}$ bond fission in the $\mathrm{NO}_{2}$ group yielding 2-nitrosopropene and $\mathrm{OH}$ radicals.

$$
\begin{aligned}
\mathrm{CH}_{3} \mathrm{C}\left(\mathrm{NO}_{2}\right) \mathrm{CH}_{3} & \rightarrow \mathrm{CH}_{3} \mathrm{C}\left(\mathrm{NO}_{2} \mathrm{H}\right) \mathrm{CH}_{2} \\
& \rightarrow \mathrm{OH}+\mathrm{CH}_{3} \mathrm{C}(\mathrm{N}=\mathrm{O}) \mathrm{CH}_{2}
\end{aligned}
$$

Due to its low barrier, this channel is expected to occur in this system, but our previous study found no signal at $\mathrm{m} / \mathrm{e}=71$ $\left(\mathrm{CH}_{3} \mathrm{C}(\mathrm{N}=\mathrm{O}) \mathrm{CH}_{2}^{+}\right)$and we were thus unable to definitively confirm this channel's existence. However, in the new study at the NSRRC, we acquired strong signal at $\mathrm{m} / \mathrm{e}=71$ $\left(\mathrm{CH}_{3} \mathrm{C}(\mathrm{N}=\mathrm{O}) \mathrm{CH}_{2}^{+}\right)$. The $m / e=71$ TOF spectrum is presented in Figure 12, and the peak is both relatively fast and extremely narrow. Because almost all of the data in this system are fit using an isotropic angular distribution, we tried to fit this channel similarly. However, this angular distribution

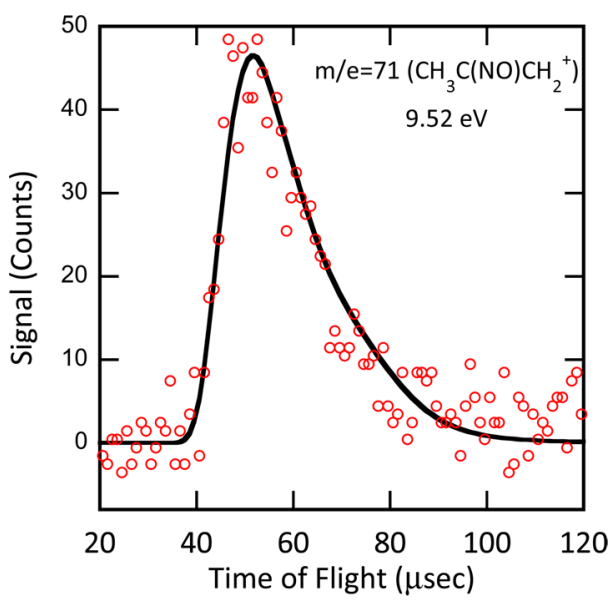

Figure 12. Time-of-flight spectrum taken at $m / e=71, \mathrm{CH}_{3} \mathrm{C}(\mathrm{NO})=$ $\mathrm{CH}_{2}{ }^{+}$, at a source angle of $10^{\circ}$ and a photoionization energy of 9.52 $\mathrm{eV}$. Data are shown in red circles. The $\mathrm{CH}_{3} \mathrm{C}(\mathrm{NO})=\mathrm{CH}_{2}$ fragments arising from secondary dissociation of vibrationally excited 2-nitro-2propyl radicals are shown by the black line fit. The fit is calculated using the $P\left(E_{\mathrm{T}}, 2^{\circ}\right)$ and secondary angular distribution shown in Figures 15 and 14, respectively.

predicts a TOF spectrum that is significantly broader than the peak in the $m / e=71$ TOF spectrum; in addition, the predicted speeds for the cofragment $(\mathrm{OH})$ are too fast for the $m / e=17$ TOF spectrum shown in Figure 13 using this angular distribution (this fit is shown in the Supporting Information as Figure S8). The only angular distribution capable of predicting a sufficiently narrow peak was a nonsymmetric forward-backward distribution where one fragment $\left(\mathrm{CH}_{3} \mathrm{C}\right.$ $\left.(\mathrm{N}=\mathrm{O}) \mathrm{CH}_{2}\right)$ is fit with a forward-scattered angular distribution and the cofragment $(\mathrm{OH})$ is fit with the corresponding backward scattered distribution. Forward convolution fitting using the angular distribution given in Figure 14, the secondary $P\left(E_{\mathrm{T}}\right)$ in Figure 15 , and the entirety of the primary $\mathrm{C}-\mathrm{Br}$ $P\left(E_{\mathrm{T}}\right)$ in Figure 6 gives the black line fit shown in the $m / e=71$ TOF and the purple line fit in the $m / e=17$ TOF spectra (Figures 12 and 13, respectively). Further evidence for this 


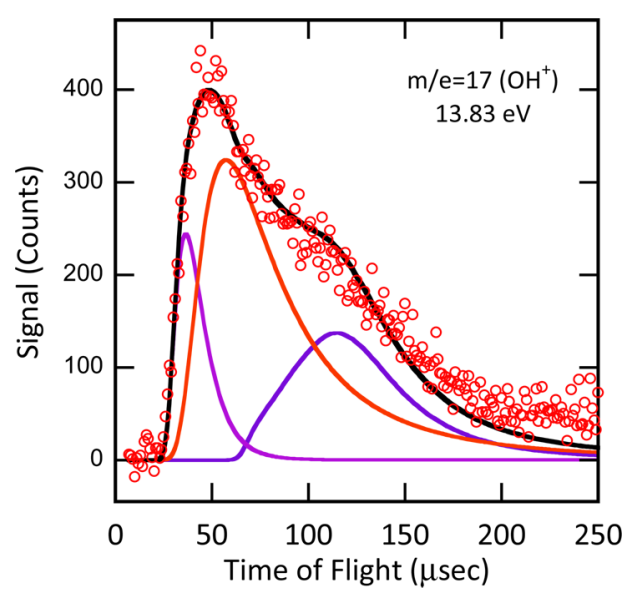

Figure 13. Time-of-flight spectrum taken at $m / e=17, \mathrm{OH}^{+}$, at a source angle of $10^{\circ}$ and a photoionization energy of $13.83 \mathrm{eV}$. Data are shown in red circles. The orange fit shows the contribution of $\mathrm{OH}$ products from the dissociation of the vibrationally hot HONO photoelimination products of eq 2 and is calculated from the $P\left(E_{\mathrm{T}}, 2^{\circ}\right)$ in Figure $\mathrm{S} 15$ (Supporting Information). The purple fit shows signal from the $\mathrm{OH}+\mathrm{CH}_{3} \mathrm{C}(\mathrm{NO})=\mathrm{CH}_{2}$ dissociation channel of vibrationally hot $\mathrm{CH}_{3} \mathrm{C}\left(\mathrm{NO}_{2}\right) \mathrm{CH}_{3}$ radicals (following primary $\mathrm{C}-\mathrm{Br}$ photofission) and is calculated from the $P\left(E_{\mathrm{T}}, 2^{\circ}\right)$ and secondary angular distribution shown in Figures 15 and 14, respectively. The blue fit peaking near $120 \mu \mathrm{sec}$ represents dissociative ionization of clusters in the molecular beam.

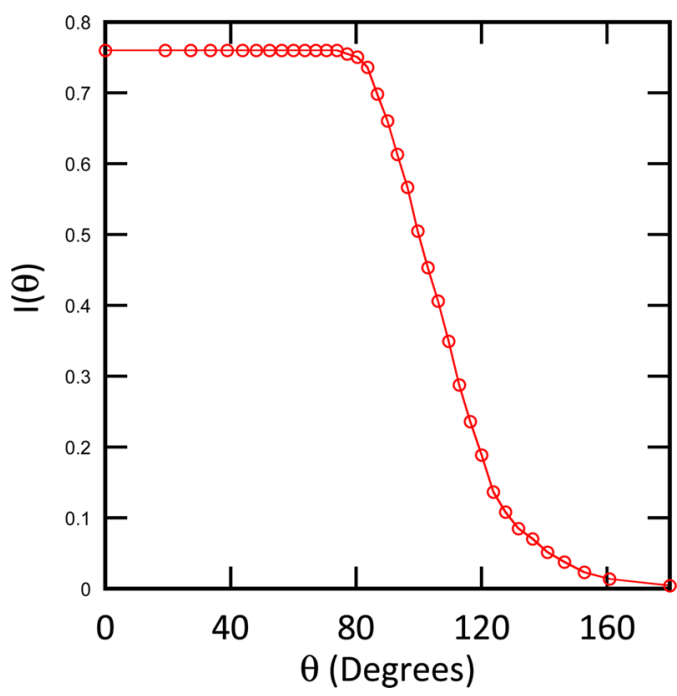

Figure 14. Secondary angular distribution for the $\mathrm{OH}$ fragments formed from the dissociation of vibrationally hot 2-nitro-2-propyl radicals to $\mathrm{OH}+\mathrm{CH}_{3} \mathrm{C}(\mathrm{NO})=\mathrm{CH}_{2}$. The angular distribution for its cofragment $\left(\mathrm{CH}_{3} \mathrm{C}(\mathrm{NO})=\mathrm{CH}_{2}\right)$ is the mirror image of this one where the mirror plane is $90^{\circ}$. Forward convolution fitting using this angular distribution and the $P\left(E_{\mathrm{T}}, 2^{\circ}\right)$ in Figure 15 gives the black line fit in the $m / e=71$ TOF spectrum (Figure 12) and the purple line fit in the $m / e=17$ TOF spectrum (Figure 13).

angular distribution is given by the purple line fit in the Chicago $m / e=17$ TOF spectrum, shown in Figure S9, Supporting Information, using the same angular distribution and $P\left(E_{\mathrm{T}}\right)$ shown in Figures 14 and 15, respectively. Though this $P\left(E_{\mathrm{T}}\right)$ is slightly faster than one might expect for a simple bond fission process, this distribution of kinetic energies is the only $P\left(E_{\mathrm{T}}\right)$ that provides an acceptable fit to both fragments in this channel.

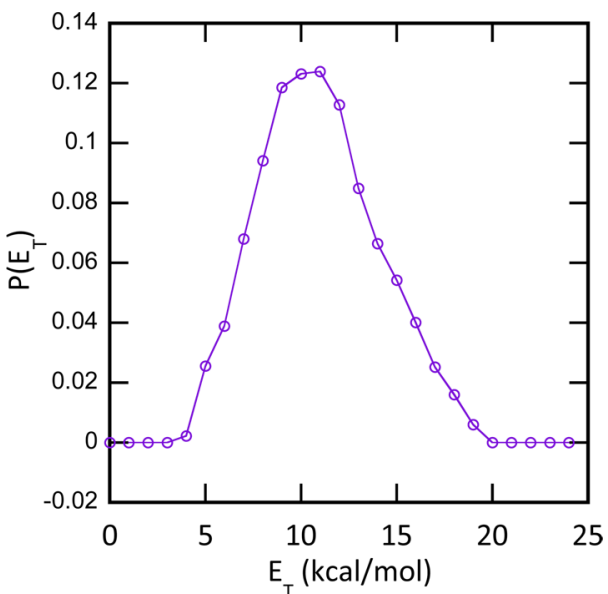

Figure 15. Product recoil kinetic energy distribution for the unimolecular dissociation of the 2-nitro-2-propyl radical to $\mathrm{OH}+$ $\mathrm{CH}_{3} \mathrm{C}(\mathrm{NO})=\mathrm{CH}_{2}$ (eq 7). The $P\left(E_{\mathrm{T}}, 2^{\circ}\right)$ is derived, along with its corresponding angular distribution in Figure 14, using forward convolution fitting of the black fit in the $m / e=71$ TOF spectrum (Figure 12) and the purple fit in the $m / e=17$ TOF spectrum (Figure $13)$.

C. Dissociation of the $\mathrm{CH}_{3} \mathrm{C}\left(\mathrm{NO}_{2}\right) \mathrm{CH}_{3}$ Radical to HONO + $\mathrm{CH}_{3} \mathrm{CCH}_{2}$. After an $\mathrm{H}$-shift from the terminal carbon to one of the oxygen atoms, the 2-nitro-2-propyl radical can lose HONO with a barrier of $34.6 \mathrm{kcal} / \mathrm{mol}$ (Figure 11).

$$
\begin{aligned}
\mathrm{CH}_{3} \mathrm{C}\left(\mathrm{NO}_{2}\right) \mathrm{CH}_{3} & \rightarrow \mathrm{CH}_{3} \mathrm{C}\left(\mathrm{NO}_{2} \mathrm{H}\right) \mathrm{CH}_{2} \\
& \rightarrow \mathrm{HONO}+\mathrm{CH}_{3} \mathrm{CCH}_{2}
\end{aligned}
$$

Signal at $m / e=41\left(\mathrm{CH}_{3} \mathrm{CCH}_{2}^{+}\right)$and $m / e=47\left(\mathrm{HONO}^{+}\right)$ evidence this channel. Forward convolution fitting using the secondary $P\left(E_{\mathrm{T}}\right)$ in Figure 16 and the entire primary $\mathrm{C}-\mathrm{Br}$ fission $P\left(E_{\mathrm{T}}\right)$ (Figure 6) gives the green fit in the $m / e=41$ and $m / e=47$ TOF spectra (Figures 10 and 17). Although this $P\left(E_{\mathrm{T}}\right)$ is slightly slower than the previous study predicted, this change is most likely due to the large differences in the $P\left(E_{\mathrm{T}}\right)$ for the initial photodissociation process $(\mathrm{C}-\mathrm{Br}$ fission $)$. This fit

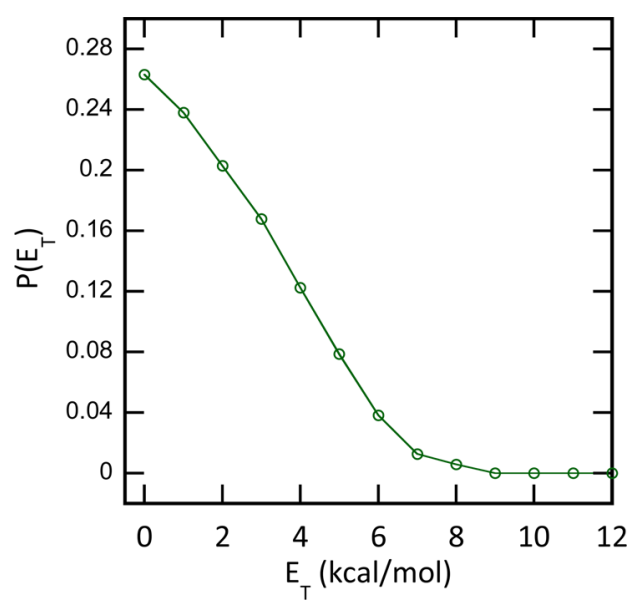

Figure 16. Product recoil kinetic energy distribution for the unimolecular dissociation of the 2-nitro-2-propyl radical to HONO $+\mathrm{CH}_{3} \mathrm{CCH}_{2}$ (eq 8). It is derived from forward convolution fitting the green portions of the $m / e=41\left(\mathrm{CH}_{3} \mathrm{CCH}_{2}^{+}\right)$and $\mathrm{m} / \mathrm{e}=47$ $\left(\mathrm{HONO}^{+}\right.$) TOF spectra (Figures 10 and 17 , respectively) assuming an isotropic secondary angular distribution. 


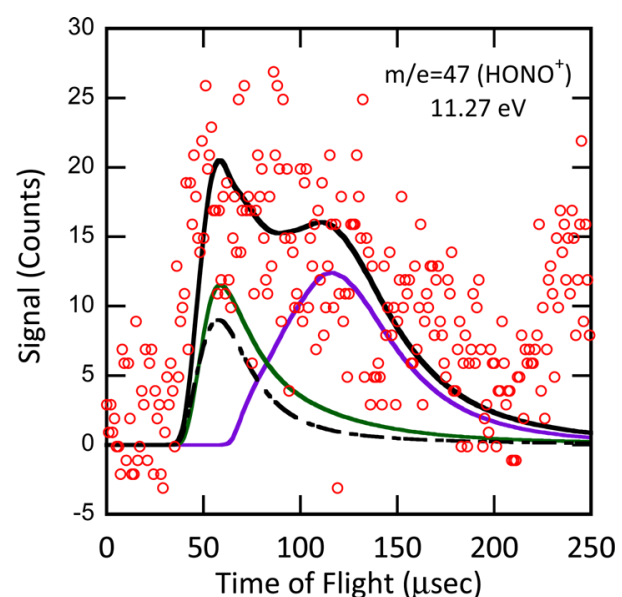

Figure 17. Time-of-flight spectrum taken at $m / e=47, \mathrm{HONO}^{+}$, at a source angle of $10^{\circ}$ and a photoionization energy of $11.27 \mathrm{eV}$. Data are shown in red circles. The green fit shows the contribution from HONO products from the dissociation of 2-nitro-2-propyl radical to $\mathrm{HONO}+\mathrm{CH}_{3} \mathrm{CCH}_{2}$ (eq 8); the fit is calculated using the primary $\mathrm{C}-$ Br photofission $P\left(E_{\mathrm{T}}\right)$ and the $P\left(E_{\mathrm{T}}, 2^{\circ}\right)$ in Figure 16. The dashed-dot black fit shows the contribution from HONO products arising from the dissociation of 2-nitropropene fragments to $\mathrm{HONO}+\mathrm{C}_{3} \mathrm{H}_{4}$; this fit is calculated using the primary unstable $\operatorname{HBr} P\left(E_{\mathrm{T}}\right)$ shown as a dashed red line in Figure 8 and the $P\left(E_{\mathrm{T}}, 2^{\circ}\right)$ in Figure $S 12$ (Supporting Information). The purple fit is the contribution from clusters in the molecular beam. Due to the moderate $\mathrm{S}: \mathrm{N}$, the scaling of these fits is arbitrary to fit the data. NOTE: This TOF was taken at an excimer laser power of $8 \mathrm{~mJ} /$ pulse rather than the $4-5 \mathrm{~mJ} /$ pulse used for all of the other TOF spectra.

can also be seen in the Chicago $m / e=41$ TOF spectrum shown in Figure S5, Supporting Information.

D. Dissociation of the $\mathrm{CH}_{3} \mathrm{C}\left(\mathrm{NO}_{2}\right) \mathrm{CH}_{3}$ Radical to $\left(\mathrm{CH}_{3}\right)_{2} \mathrm{CO}$ + NO. Vibrationally excited 2-nitro-2-propyl radicals can undergo a concerted isomerization and NO loss pathway to yield $\mathrm{NO}+$ acetone.

$$
\begin{aligned}
\mathrm{CH}_{3} \mathrm{C}\left(\mathrm{NO}_{2}\right) \mathrm{CH}_{3} & \rightarrow \mathrm{CH}_{3} \mathrm{C}(\mathrm{O})(\mathrm{NO}) \mathrm{CH}_{3} \\
& \rightarrow\left(\mathrm{CH}_{3}\right)_{2} \mathrm{CO}+\mathrm{NO}
\end{aligned}
$$

Because the new primary $\mathrm{C}-\mathrm{Br} P\left(E_{\mathrm{T}}\right)$ shown in Figure 6 is different from the one we used in our previous study, we must refit this secondary channel. Rather than adjust the secondary $P\left(E_{\mathrm{T}}\right)$ (as we did in section C) we refit these data with a modified secondary angular distribution. In our previous work, we fit the NO loss channel with a sideways scattered secondary angular distribution, which was adjusted to fit our new signal. The new angular distribution (shown in Figure 19) is less severe at the end points but still shows a sideways scattered event because $I(\theta)$ peaks at $90^{\circ}$ and decreases symmetrically to $0^{\circ}$ and $180^{\circ}$. Forward convolution fitting using the entire $\mathrm{C}-\mathrm{Br}$ photofission $P\left(E_{\mathrm{T}}\right)$ (Figure 6), the secondary $P\left(E_{\mathrm{T}}\right)$ (Figure 18 ), and the secondary angular distribution (Figure 19) gives the blue fit in the $m / e=30 P(v)$ shown in Figure 20. These $P\left(E_{\mathrm{T}}\right)$ 's and secondary angular distribution also predict the blue line fit shown on the $m / e=30$ TOF spectrum in the Supporting Information (Figure S10) along with the fits resulting from the multitude of other neutral and dissociative ionization events that give $\mathrm{NO}^{+}$as a product. Furthermore, there is no other secondary channel that can produce NO fragments with high enough translational energy to fit this peak in its entirety, adding evidence to this assignment.

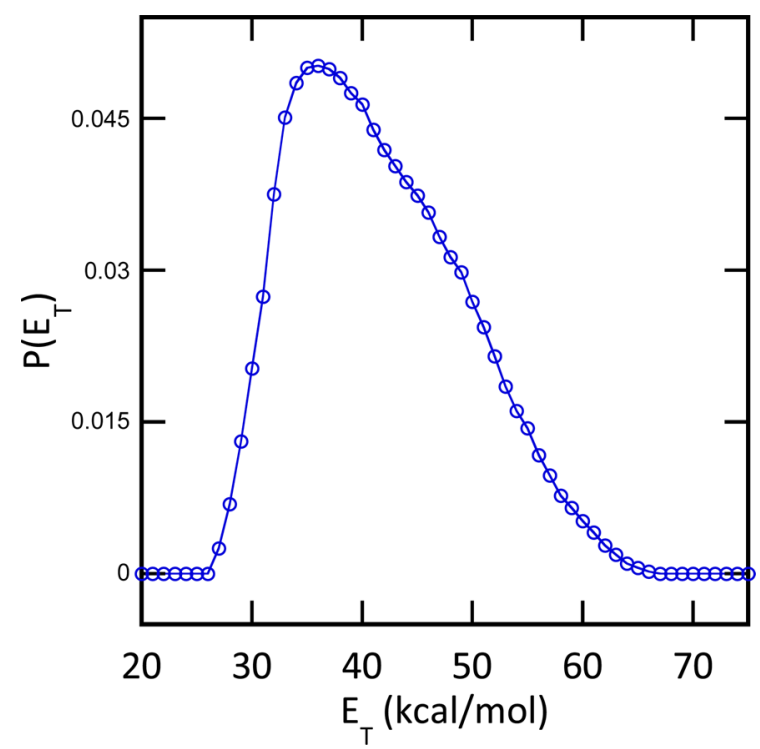

Figure 18. Product recoil kinetic energy distribution for the unimolecular dissociation of 2-nitro-2-propyl $\left(\mathrm{CH}_{3} \mathrm{C}\left(\mathrm{NO}_{2}\right) \mathrm{CH}_{3}\right)$ radical to $\mathrm{NO}+\mathrm{CH}_{3} \mathrm{C}(\mathrm{O}) \mathrm{CH}_{3}$ (eq 9). The combination of this $P\left(E_{\mathrm{T}}, 2^{\circ}\right)$ and the angular distribution in Figure 19 are used to generate the blue fits in Figures 20, 21, and 22.

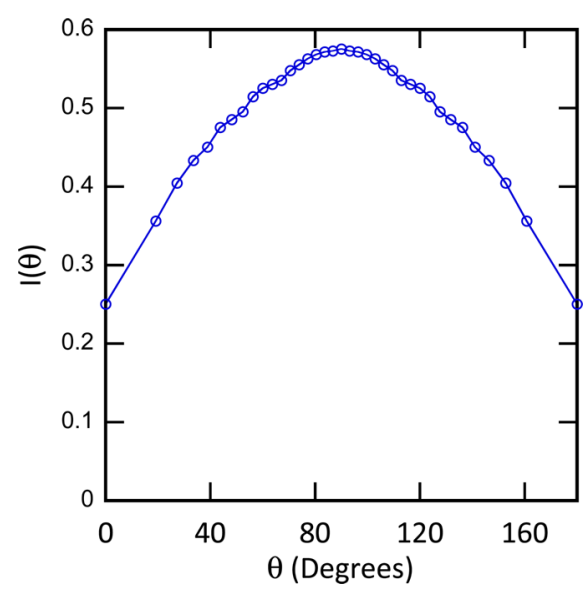

Figure 19. Secondary angular distribution for the secondary dissociation of vibrationally excited $\mathrm{CH}_{3} \mathrm{C}\left(\mathrm{NO}_{2}\right) \mathrm{CH}_{3}$ to $\mathrm{NO}+$ $\mathrm{CH}_{3} \mathrm{C}(\mathrm{O}) \mathrm{CH}_{3}$ (eq 9).

In our previous study, there was no signal from the cofragment of this channel (acetone) at its parent mass $[\mathrm{m} / \mathrm{e}$ $\left.=58\left(\left(\mathrm{CH}_{3}\right)_{2} \mathrm{CO}^{+}\right)\right]$on either apparatus. It was therefore concluded that the acetone fragments were sufficiently vibrationally excited to undergo exclusive dissociative ionization, with the vast majority going to $\mathrm{CH}_{3} \mathrm{CO}^{+}+\mathrm{CH}_{3}$. To further corroborate this, no signal was found at $\mathrm{m} / \mathrm{e}=58$ $\left(\left(\mathrm{CH}_{3}\right)_{2} \mathrm{CO}^{+}\right)$at the NSRRC despite a relatively low photoionization energy of $10.0 \mathrm{eV}$ (above the $9.7 \mathrm{eV}$ IE of acetone but below the dissociative ionization threshold). As observed previously, strong signal was found at $m / e=43$ $\left(\mathrm{CH}_{3} \mathrm{CO}^{+}\right)$at photoionization energies down to $9.84 \mathrm{eV}$. Forward convolution fitting using the same secondary $P\left(E_{\mathrm{T}}\right)$ and angular distribution used to fit the $\mathrm{NO}^{+}$fragment gives the fit on the $m / e=43$ TOF spectra from the NSRRC and from Chicago (Figure 21, upper and lower frames respectively). If the $\mathrm{CH}_{3} \mathrm{CO}$ radicals were formed in a neutral dissociation process, there would be additional translational energy 


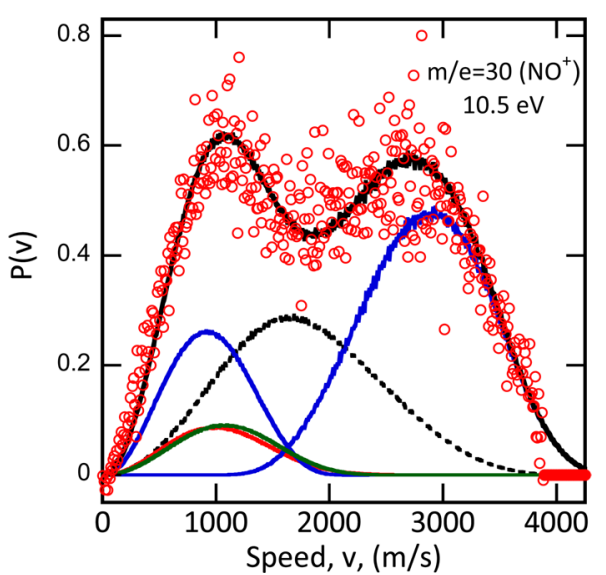

Figure 20. Speed distribution derived from the $m / e=30\left(\mathrm{NO}^{+}\right)$ image. Data are shown in red circles. The sharp drop just below 4000 $\mathrm{m} / \mathrm{s}$ is from the products being scattered off the active area of the detector. The contribution from the NO product from the dissociation of 2-nitro-2-propyl radicals to $\mathrm{NO}+$ acetone (eq 9) is fit by the fast blue line using the $P\left(E_{\mathrm{T}}, 2^{\circ}\right)$ shown in Figure 18. The contribution of $\mathrm{NO}$ products from the dissociation of 2-nitropropene to $\mathrm{NO}+$ $\mathrm{CH}_{3} \mathrm{C}(\mathrm{O}) \mathrm{CH}_{2}$ (eq 12) is shown as the double dash-dot black fit; this fit uses the $P\left(E_{\mathrm{T}}, 2^{\circ}\right)$ in Figure S12 (Supporting Information). The NO resulting from unimolecular dissociation of vibrationally hot HONO fragments formed upon primary HONO elimination is shown by the orange fit and uses the $P\left(E_{T}, 2^{\circ}\right)$ in Figure S15 (Supporting Information). The $\mathrm{NO}$ via secondary photodissociation of $\mathrm{NO}_{2}$ products formed from primary $\mathrm{C}-\mathrm{NO}_{2}$ photofission is shown as the short dash black line and uses the $P\left(E_{\mathrm{T}}, 2^{\circ}\right)$ in Figure S17 (Supporting Information). The $\mathrm{NO}$ formed from the unimolecular dissociation of $\mathrm{NO}_{2}$ products formed from primary $\mathrm{C}-\mathrm{NO}_{2}$ photofission is show as the slower blue line and uses the $P\left(E_{\mathrm{T}}, 2^{\circ}\right)$ shown in Figure S18 (Supporting Information).

partitioned into the resulting fragments $\left(\mathrm{CH}_{3}\right.$ and $\left.\mathrm{CH}_{3} \mathrm{CO}\right)$. Because no additional translational energy is needed to fit the $m / e=43$ TOF spectra, two conclusions can be drawn: the acetone fragments do not appear at $m / e=58$ due to a dissociative ionization process, and the acetone fragments are sufficiently vibrationally excited to dissociatively ionize at energies below the $\mathrm{AE}$ of $\mathrm{CH}_{3} \mathrm{CO}^{+}$from acetone. Further evidence for the high internal excitation of acetone is the appearance of signal (shown as the dashed blue line in Figure 22) from this channel at $m / e=42\left(\mathrm{C}_{2} \mathrm{H}_{2} \mathrm{O}^{+}\right)$in the TOF spectrum taken at $10.42 \mathrm{eV}$ from the NSRRC. Further description of this dissociative ionization pathway is given in the Supporting Information.

E. No Dissociation of the $\mathrm{CH}_{3} \mathrm{C}\left(\mathrm{NO}_{2}\right) \mathrm{CH}_{3}$ Radical to $\left(\mathrm{CH}_{3} \mathrm{C}\left(\mathrm{NO}_{2}\right)=\mathrm{CH}_{2}\right)+\mathrm{H}$. Although the internally excited 2nitro-2-propyl radicals were previously postulated to undergo an $\mathrm{H}$-loss pathway with a barrier of $42.5 \mathrm{kcal} / \mathrm{mol}$ (Figure 11) due to unfit signal at $m / e=41$ and $m / e=30$ (the dominant dissociative ionization fragments expected from $\mathrm{CH}_{3} \mathrm{C}\left(\mathrm{NO}_{2}\right)$ $\mathrm{CH}_{2}$ ), this signal is now fit by the dissociative ionization of stable $\mathrm{CH}_{3} \mathrm{C}\left(\mathrm{NO}_{2}\right) \mathrm{CH}_{2}$ fragments arising from primary $\mathrm{HBr}$ photoelimination discussed in section 1E. Because this channel is the second highest barrier for these radicals, it is not surprising that it does not occur to a large extent in this system.

3. Dissociation of Vibrationally Excited $\mathrm{CH}_{3} \mathrm{C}\left(\mathrm{NO}_{2}\right) \mathrm{CH}_{2}$ Resulting from Primary $\mathrm{HBr}$ Elimination. A. Overview. Our previous study ${ }^{22}$ showed that the vibrationally excited 2nitropropene fragments formed by $\mathrm{HBr}$ photoelimination underwent two subsequent dissociation channels: HONO

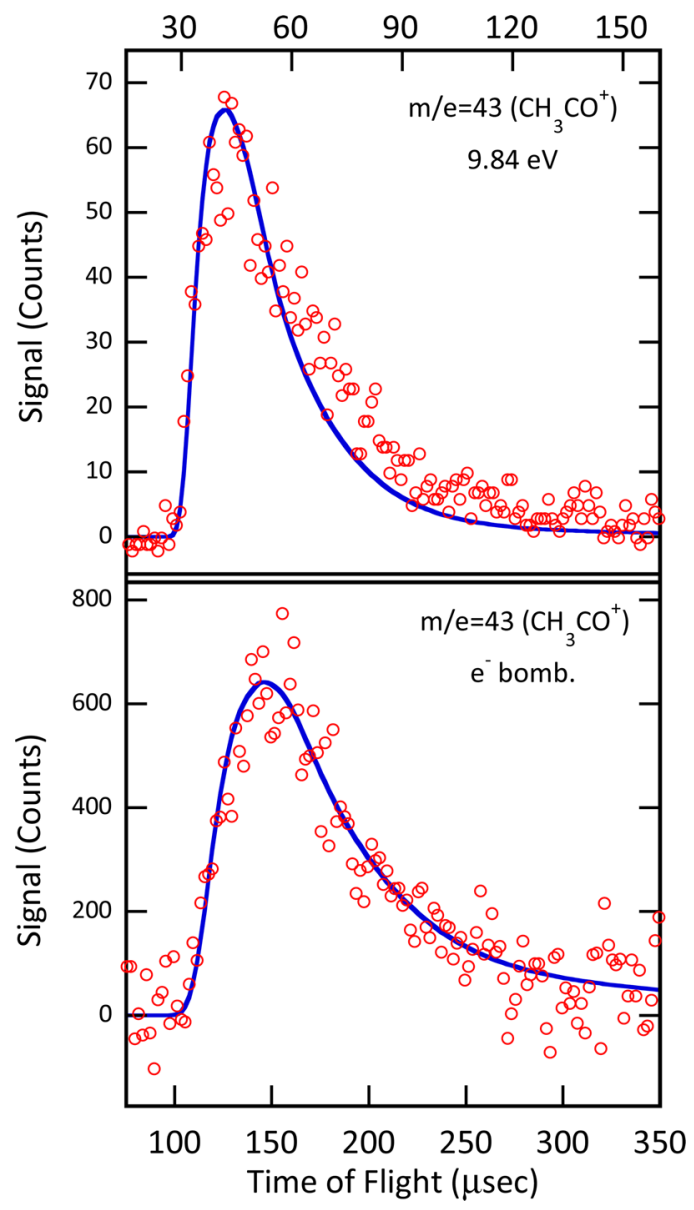

Figure 21. Time-of-flight spectrum taken at $m / e=43, \mathrm{CH}_{3} \mathrm{CO}^{+}$, at a source angle of $20^{\circ}$ using two different detection methods. Upper frame: acquired at a photoionization energy of $9.84 \mathrm{eV}$. The data are shown in red circles. NOTE: The time-of-flight axis is above the upper frame. Lower frame: acquired using electron bombardment at $200 \mathrm{eV}$. This signal arises from dissociative ionization of $\mathrm{CH}_{3} \mathrm{C}(\mathrm{O}) \mathrm{CH}_{3}$ fragments formed via secondary dissociation of vibrationally excited $\mathrm{CH}_{3} \mathrm{C}\left(\mathrm{NO}_{2}\right) \mathrm{CH}_{3}$ to $\mathrm{NO}+\mathrm{CH}_{3} \mathrm{C}(\mathrm{O}) \mathrm{CH}_{3}$ (eq 9). The forward convolution fit shown in blue gives the $P\left(E_{T}, 2^{\circ}\right)$ and secondary angular distribution shown in Figures 18 and 19, respectively. The remaining unfit signal is too slow to arise from this channel and is presumed to be contributions from molecular clusters.

loss to give either allene or propyne and NO loss following a nitro-nitrite isomerization. In the previous study using electron bombardment ionization, we were unable to detect $\mathrm{HONO}$ at $\mathrm{HONO}^{+}$and could only detect its dissociative ionization fragments of $\mathrm{OH}^{+}$and $\mathrm{NO}^{+}$. However, in our current study employing tunable VUV, we were able to detect $\mathrm{HONO}^{+}$using a photoionization energy of $11.27 \mathrm{eV}$. In addition to these two secondary channels, the nascent $\mathrm{CH}_{3} \mathrm{C}(\mathrm{O}) \mathrm{CH}_{2}$ radicals (formed after $\mathrm{NO}$ loss) undergo unimolecular dissociation to $\mathrm{CH}_{3}$ and ketene. Due to the coincidental similarity of the unstable $\operatorname{HBr} P\left(E_{\mathrm{T}}\right)$ shown as dashed red line in Figure 2 and the $\operatorname{HBr} P\left(E_{\mathrm{T}}\right)$ derived previously (section $1 \mathrm{E}$ ), the corresponding secondary and tertiary $P\left(E_{\mathrm{T}}\right)$ 's for these three channels do not change appreciably. The calculated PES for 2nitropropene may be found in our previous study ${ }^{22}$ as Figure 20.

B. Dissociation of $\mathrm{CH}_{3} \mathrm{C}\left(\mathrm{NO}_{2}\right) \mathrm{CH}_{2}$ to $\mathrm{HONO}+\mathrm{C}_{3} \mathrm{H}_{4}$. The lowest energy pathway available for 2-nitropropene is $\mathrm{HONO}$ 


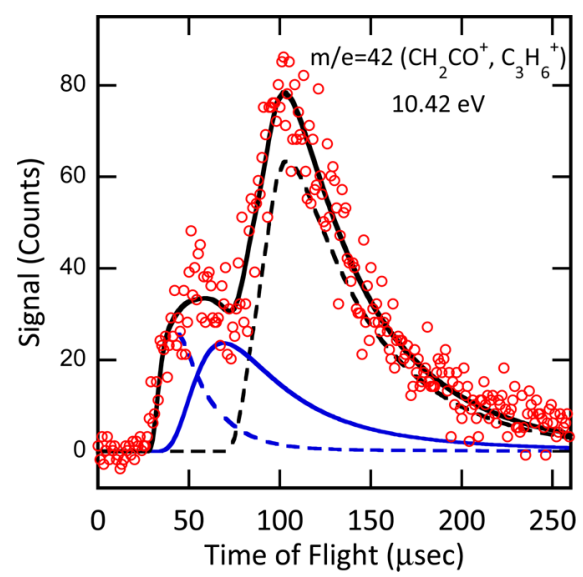

Figure 22. Time-of-flight spectrum taken at $m / e=42, \mathrm{CH}_{2} \mathrm{CO}^{+}$and $\mathrm{CH}_{3} \mathrm{CH}=\mathrm{CH}_{2}{ }^{+}$, at a source angle of $20^{\circ}$ and a photoionization energy of $9.84 \mathrm{eV}$. The solid blue fit is the contribution of ketene fragments formed from the tertiary dissociation of vibrationally excited $\mathrm{CH}_{3} \mathrm{C}(\mathrm{O}) \mathrm{CH}_{2}$ fragments. Forward convolution of the solid blue line fit gives the $P\left(E_{\mathrm{T}}, 3^{\circ}\right)$ shown in Figure $S 14$ (Supporting Information). Dissociative ionization of $\mathrm{CH}_{3} \mathrm{C}(\mathrm{Br}) \mathrm{CH}_{3}$ fragments resulting from primary $\mathrm{C}-\mathrm{NO}_{2}$ photofission is shown by the dashed black fit and is described fully in the Supporting Information. The signal peaking at $\sim 40 \mu$ s fit with the dashed blue line shows the contribution from the dissociative ionization of $\mathrm{CH}_{3} \mathrm{C}(\mathrm{O}) \mathrm{CH}_{3}$ fragments from the dissociation of the 2-nitro-2-propyl radical to $\mathrm{NO}+\mathrm{CH}_{3} \mathrm{C}(\mathrm{O}) \mathrm{CH}_{3}$; this fit is derived using the $P\left(E_{\mathrm{T}}, 2^{\circ}\right)$ and secondary angular distribution shown in Figures 18 and 19, respectively.

loss yielding HONO (mass 47) and propyne or allene (mass 40) with barriers of 53.7 and $54.8 \mathrm{kcal} / \mathrm{mol}$, respectively. ${ }^{22}$

$$
\mathrm{CH}_{3} \mathrm{C}\left(\mathrm{NO}_{2}\right) \mathrm{CH}_{2} \rightarrow \mathrm{HONO}+\mathrm{C}_{3} \mathrm{H}_{4}
$$

Evidence for this channel is given by signal at $m / e=47$ $\left(\mathrm{HONO}^{+}\right)$in Figure 17 and $m / e=40\left(\mathrm{C}_{3} \mathrm{H}_{4}^{+}\right)$in Figure 23. In

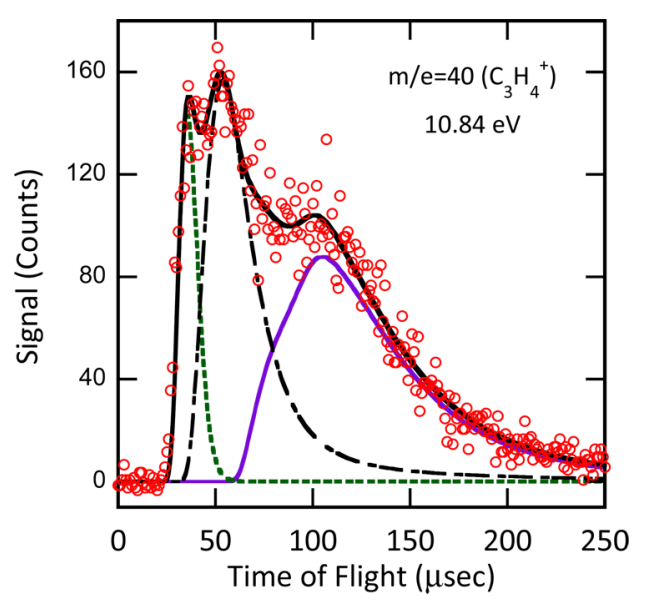

Figure 23. Time-of-flight spectrum taken at $m / e=40\left(\mathrm{C}_{3} \mathrm{H}_{4}{ }^{+}\right)$at a source angle of $20^{\circ}$ and a photoionization energy of $10.84 \mathrm{eV}$. Data are shown in red circles. The contribution of $\mathrm{C}_{3} \mathrm{H}_{4}$ products from the unimolecular dissociation of 2-nitropropene to $\mathrm{HONO}+\mathrm{C}_{3} \mathrm{H}_{4}$ (eq $10)$ is shown in the dash-dot black fit. Forward convolution of the signal from the dash-dot fit gives the $P\left(E_{\mathrm{T}}, 2^{\circ}\right)$ shown in Figure $S 12$ (Supporting Information). The dashed green line fit shows the contribution of $\mathrm{C}_{3} \mathrm{H}_{4}$ fragments from the dissociation of 2bromopropene to $\mathrm{C}_{3} \mathrm{H}_{4}+\mathrm{HBr}$ (eq 13). Forward convolution of the dashed green line fit gives the $P\left(E_{\mathrm{T}}, 2^{\circ}\right)$ shown in Figure $\mathrm{S} 16$ (Supporting Information). our previous study, we were unable to acquire any signal at $m / e$ $=47$ and were forced to rely on fitting HONO via its dissociative ionization channels and a $m / e=40 P(v)$ with extremely poor S:N. The $m / e=47$ TOF spectrum has modest $\mathrm{S}: \mathrm{N}$; so it is difficult to use diagnostically but the $m / e=40$ $\left(\mathrm{C}_{3} \mathrm{H}_{4}^{+}\right)$TOF spectrum in Figure 23 shows clear and welldefined bimodality. We can confirm the dissociation of 2nitropropene to $\mathrm{HONO}+\mathrm{C}_{3} \mathrm{H}_{4}$ by noting that the $\mathrm{HONO}$ and $\mathrm{C}_{3} \mathrm{H}_{4}$ fragments must be momentum matched. If we try to assign the fastest peak at $m / e=40$ to eq 10 , the cofragment (HONO) is predicted to be too fast and the fit does not lie in the broad peak observed in the $m / e=47$ TOF spectrum. Forward convolution fitting using the primary unstable $\mathrm{HBr}$ $P\left(E_{\mathrm{T}}\right)$ (dashed red line in Figure 9) and the secondary $P\left(E_{\mathrm{T}}\right)$ given in Figure S12 (Supporting Information) gives the dashdot black fits in the $m / e=47$ (Figure 17) and $m / e=40$ TOF spectra (Figure 23). Because the slow portion of the $P\left(E_{\mathrm{T}}\right)$ from this channel is constrained by the peak shape, the excess slow signal is assigned to molecular clusters. Surprisingly, the secondary $P\left(E_{\mathrm{T}}\right)$ for this channel is very similar to that derived by us previously, despite the uncertainty inherent in the previous data analysis.

C. Dissociation of $\mathrm{CH}_{3} \mathrm{C}\left(\mathrm{NO}_{2}\right) \mathrm{CH}_{2}$ to $\mathrm{NO}+\mathrm{CH}_{3} \mathrm{C}(\mathrm{O}) \mathrm{CH}_{2}$ and $\mathrm{CH}_{3} \mathrm{C}(\mathrm{O}) \mathrm{CH}_{2}$ to $\mathrm{CH}_{3}+\mathrm{H}_{2} \mathrm{CC}=\mathrm{O}$. Vibrationally excited 2nitropropene fragments undergo a nitro--nitrite isomerization followed by $\mathrm{O}-\mathrm{N}$ bond cleavage to yield $\mathrm{NO}+\mathrm{CH}_{3} \mathrm{C}(\mathrm{O}) \mathrm{CH}_{2}$. Interestingly, it was determined previously that the resulting $\mathrm{CH}_{3} \mathrm{C}(\mathrm{O}) \mathrm{CH}_{2}$ radicals retained enough internal energy to undergo a subsequent unimolecular dissociation to $\mathrm{CH}_{3}$ and ketene.

$$
\begin{aligned}
\mathrm{CH}_{3} \mathrm{C}\left(\mathrm{NO}_{2}\right) \mathrm{CH}_{2} & \rightarrow \mathrm{CH}_{3} \mathrm{C}(\mathrm{ONO}) \mathrm{CH}_{2} \\
& \rightarrow \mathrm{CH}_{3} \mathrm{C}(\mathrm{O}) \mathrm{CH}_{2} \mathrm{NO} \\
& \rightarrow \mathrm{NO}+\mathrm{CH}_{3} \mathrm{C}(\mathrm{O}) \mathrm{CH}_{2}
\end{aligned}
$$

Forward convolution fitting using the new, "correct" unstable primary $\mathrm{HBr} P\left(E_{\mathrm{T}}\right)$ shown as a dashed red line in Figure 9 and the secondary $P\left(E_{\mathrm{T}}\right)$ detailed in Figure $\mathrm{S} 13$ (Supporting Information) gives the green line fit on the $m / e=30\left(\mathrm{NO}^{+}\right)$ $P(v)$ shown in Figure 20. The secondary $P\left(E_{\mathrm{T}}\right)$ is strikingly similar to the one derived in Chicago. ${ }^{22}$ Forward convolution fitting using the tertiary $P\left(E_{\mathrm{T}}\right)$ shown in Figure $S 14$ (Supporting Information) gives the blue fit on the $m / e=42$ $\left(\mathrm{CH}_{2} \mathrm{CO}^{+}\right)$(Figure 22) and the $m / e=15\left(\mathrm{CH}_{3}^{+}\right)$TOF spectra (Figure 24); this channel is also observed in the Chicago $\mathrm{m} / \mathrm{e}=$ $42 P(v)$ shown as the blue fit in Figure S11 (Supporting Information). Although the entirety of the fast peak in the $m / e$ $=42$ TOF spectrum (Figure 22) cannot be fit by this channel, the remainder is easily diagnosed as dissociative ionization of acetone from the secondary dissociation of 2-nitro-2-propyl radical to $\mathrm{NO}+$ acetone; this process was described fully in section $2 \mathrm{D}$.

4. Dissociation of Vibrationally Excited HONO and $\mathrm{CH}_{3} \mathrm{C}(\mathrm{Br}) \mathrm{CH}_{2}$ Resulting from Primary HONO Photoelimination. A. Overview. Following primary HONO photoelimination, the nascent HONO fragments undergo unimolecular $\mathrm{O}-\mathrm{N}$ bond fission with an endoergicity of $49.9 \mathrm{kcal} /$ $\mathrm{mol}$ and the nascent 2-bromopropene fragments undergo $\mathrm{HBr}$ loss to yield $\mathrm{HBr}$ and $\mathrm{C}_{3} \mathrm{H}_{4}$ with a barrier of $64.8 \mathrm{kcal} / \mathrm{mol}$. ${ }^{22}$ The secondary $P\left(E_{\mathrm{T}}\right)$ for $\mathrm{HONO}$ dissociation to $\mathrm{OH}+\mathrm{NO}$ is significantly slower than the previous study postulated, because some of the $\mathrm{OH}^{+}$signal is now definitively assigned to the 


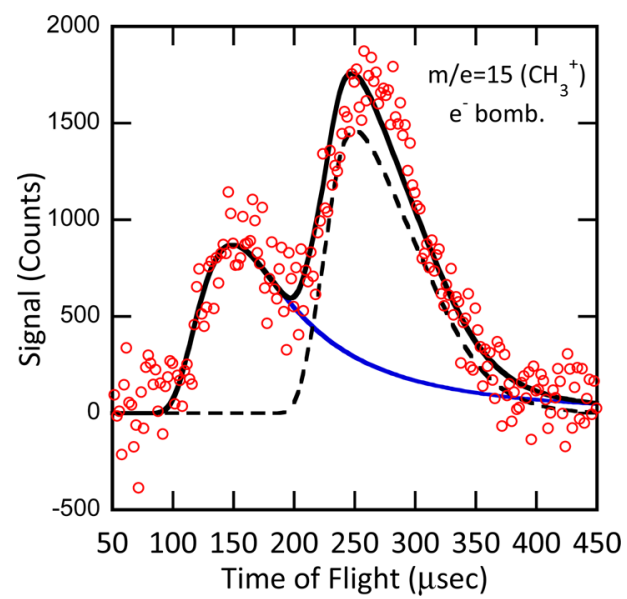

Figure 24. Time-of-flight spectrum taken at $m / e=15, \mathrm{CH}_{3}{ }^{+}$, at a source angle of $10^{\circ}$. Data are shown in red circles. The blue fit is the contribution of methyl radicals formed from the tertiary dissociation of vibrationally excited $\mathrm{CH}_{3} \mathrm{C}(\mathrm{O}) \mathrm{CH}_{2}$ fragments. Forward convolution of the blue fit gives the $P\left(E_{\mathrm{T}}, 3^{\circ}\right)$ shown in Figure $S 13$ (Supporting Information). Dissociative ionization of $\mathrm{CH}_{3} \mathrm{C}(\mathrm{Br}) \mathrm{CH}_{3}$ fragments resulting from primary $\mathrm{C}-\mathrm{NO}_{2}$ photofission is shown by the short dashed black fit and is described fully in the Supporting Information.

dissociation of 2-nitro-2-propyl radical to $\mathrm{OH}+\mathrm{CH}_{3} \mathrm{C}(\mathrm{NO})$ $\mathrm{CH}_{2}$ using the new $m / e=71\left(\mathrm{CH}_{3} \mathrm{C}(\mathrm{NO}) \mathrm{CH}_{2}^{+}\right)$signal. Additionally the high signal-to-noise at both $\mathrm{HBr}^{+}$and $\mathrm{C}_{3} \mathrm{H}_{4}^{+}$ demonstrates that there is additional translational energy imparted to the secondary $\mathrm{HBr}$ loss pathway than was predicted previously. ${ }^{22}$

B. Dissociation of HONO to $\mathrm{NO}+\mathrm{OH}$. All of the nascent HONO molecules formed from primary HONO elimination undergo unimolecular dissociation to $\mathrm{NO}$ (mass 30) and $\mathrm{OH}$ (mass 17).

$$
\mathrm{HONO} \rightarrow \mathrm{OH}+\mathrm{NO}
$$

Due to the large number of channels that yield neutral NO fragments it is difficult to use any $m / e=30\left(\mathrm{NO}^{+}\right)$signal to determine the secondary $P\left(E_{\mathrm{T}}\right)$ for this channel and thus the $m / e=17\left(\mathrm{OH}^{+}\right)$TOF spectrum must be used; the $m / e=17$ TOF spectrum from the NSRRC is shown in Figure 13 and taken at a photoionization energy of $13.83 \mathrm{eV}$ to avoid products resulting from dissociative ionization. Because the fast portion of the $m / e=17$ TOF spectrum is fit with secondary $\mathrm{OH}$ loss from another channel (section $2 \mathrm{~B}$ ), the remainder of the signal is ascribed to the HONO dissociation channel. Forward convolution fitting using the secondary $P\left(E_{\mathrm{T}}\right)$ in Figure $S 15$ (Supporting Information) and the entire HONO primary $P\left(E_{\mathrm{T}}\right)$ (ref 22, Figure 5) gives the orange fit in the $\mathrm{m} / \mathrm{e}=17$ TOF spectrum and the $m / e=30 P(v)$ (Figures 13 and 20, respectively). Because the $m / e=17$ TOF spectrum shown in Figure 13 from the NSRRC is taken near the ionization energy of $\mathrm{OH}$, there is no dissociative ionization from other fragments, giving further credence to the accuracy of secondary $P\left(E_{\mathrm{T}}\right)$ derived for this channel. The slowest signal in the $m / e=17$ TOF spectrum is ascribed to molecular clusters because it is too slow to be any other dissociation channel. Furthermore, the diagnosis of this $P\left(E_{\mathrm{T}}\right)$ is confirmed by the corresponding fit on the $m / e=17$ TOF spectrum taken at $200 \mathrm{eV}$ at Chicago, shown as the orange fit in Figure S9, Supporting Information.

C. Dissociation of $\mathrm{CH}_{3} \mathrm{C}(\mathrm{Br}) \mathrm{CH}_{2}$ To Yield $\mathrm{HBr}$ and $\mathrm{C}_{3} \mathrm{H}_{4}$. The lowest energy pathway available for vibrationally excited 2- bromopropene is loss of $\mathrm{HBr}$ with a TS barrier of $64.8 \mathrm{kcal} /$ mol.

$$
\mathrm{CH}_{3} \mathrm{C}(\mathrm{Br}) \mathrm{CH}_{2} \rightarrow \mathrm{HBr}+\mathrm{C}_{3} \mathrm{H}_{4}
$$

The $\mathrm{HBr}$ fragment arising from eq 13 is difficult to definitively identify because the $m / e=80,82\left(\mathrm{HBr}^{+}\right)$TOF spectra have significant contribution arising from primary $\mathrm{HBr}$ photoelimination (section $1 \mathrm{E}$ ). Consequently, it is necessary to use signal arising from the $\mathrm{C}_{3} \mathrm{H}_{4}{ }^{+}$fragments $(\mathrm{m} / \mathrm{e}=40)$. In our previous study, the only signal at $m / e=40$ was a $P(v)$ from the imaging apparatus, which had poor signal-to-noise; so it was difficult to assign an accurate $P\left(E_{\mathrm{T}}\right)$ for this channel. However, the $m / e=40$ TOF spectrum acquired at the NSRRC at a photoionization energy of $10.84 \mathrm{eV}$ (Figure 23) has excellent S:N and clearly shows two peaks. The other source of $m / e=40$ fragments is HONO elimination from 2-nitropropene (discussed in section 3B), and this channel is not capable of possessing enough translational energy to fit the fast peak in the $m / e=40$ TOF spectrum. Therefore, the fast peak is ascribed to this channel. Forward convolution fitting using the primary HONO $P\left(E_{\mathrm{T}}\right)$ (ref 22, Figure 4) and the secondary $P\left(E_{\mathrm{T}}\right)$ in Figure S16 (Supporting Information) gives the dashed green fit shown in Figure 23. Using this $P\left(E_{\mathrm{T}}\right)$ to predict the TOF spectrum of the $\mathrm{HBr}$ cofragment yields the dashed green fit in the $m / e=82\left(\mathrm{HBr}^{+}\right)$TOF spectrum (Figure 8). This secondary channel clearly fits well on the fast edge of the $\mathrm{HBr}^{+}$TOF spectrum and provides unambiguous evidence both for this channel's occurrence and for its respective $P\left(E_{\mathrm{T}}\right)$.

5. Dissociation of Vibrationally Excited $\mathbf{N O}_{2}$ and $\mathrm{CH}_{3} \mathrm{C}(\mathrm{Br}) \mathrm{CH}_{3}$ Resulting from Primary $\mathrm{C}-\mathrm{NO}_{2}$ Photofission. A. Overview. Following $\mathrm{C}-\mathrm{NO}_{2}$ photofission, both the $\mathrm{NO}_{2}$ and $\mathrm{CH}_{3} \mathrm{C}(\mathrm{Br}) \mathrm{CH}_{3}$ radicals undergo subsequent dissociative events. The nascent $\mathrm{NO}_{2}$ fragments undergo either secondary photodissociation to $\mathrm{NO}$ and $\mathrm{O}$ or unimolecular dissociation to the same products with a barrier of $72 \mathrm{kcal} / \mathrm{mol}$. The $\mathrm{CH}_{3} \mathrm{C}(\mathrm{Br}) \mathrm{CH}_{3}$ radicals can undergo an $\mathrm{H}$-loss channel with an endoergicity of $37.9 \mathrm{kcal} / \mathrm{mol}$ or dissociatively ionize to $\mathrm{CH}_{3} \mathrm{CCH}_{2}{ }^{+}(\mathrm{AE}=9.2 \mathrm{eV})$ and $\mathrm{CH}_{3} \mathrm{CHCH}_{2}{ }^{+}(\mathrm{AE}=10.2 \mathrm{eV})$. The low bond dissociation energy for the initial photodissociation $(55 \mathrm{kcal} / \mathrm{mol})$ and the small amount of translational energy partitioned into the resulting fragments $(<20$ $\mathrm{kcal} / \mathrm{mol}$ ) allows for sufficient energy for all of the possible dissociative channels. Details regarding the secondary channels other than the secondary photodissociation channel discussed below (section $5 \mathrm{~B}$ ) are given in the Supporting Information.

B. Photodissociation of $\mathrm{NO}_{2}$ To Yield $\mathrm{NO}+\mathrm{O}$. This channel is confirmed by the presence of a very fast peak at $m / e=16$ $\left(\mathrm{O}^{+}\right)$at $14.59 \mathrm{eV}$.

$$
\mathrm{NO}_{2}+h v \rightarrow \mathrm{NO}+\mathrm{O}
$$

This $m / e=16$ TOF spectrum is shown in Figure 25 and clearly shows the presence of both a fast peak and a broad slow peak. Forward convolution fitting using the primary "unstable" $\mathrm{NO}_{2}$ $P\left(E_{\mathrm{T}}\right)$ shown in green in Figure 2 (section 1B) and the secondary $P\left(E_{\mathrm{T}}\right)$ (shown in the Supporting Information as Figure S17) gives the short dashed black line fit in the $m / e=16$ TOF spectrum (Figure 25). Furthermore, the $P\left(E_{\mathrm{T}}\right)$ used to fit this channel is directly reproduced from a study by Butler et al., ${ }^{20}$ on the photodissociation of nitromethane, for this same process. This fit lines up with the fast edge of the spectrum and peaks at the inflection point of the two contributions. Though the $P\left(E_{\mathrm{T}}\right)$ 's involved in this dissociation did not change from 


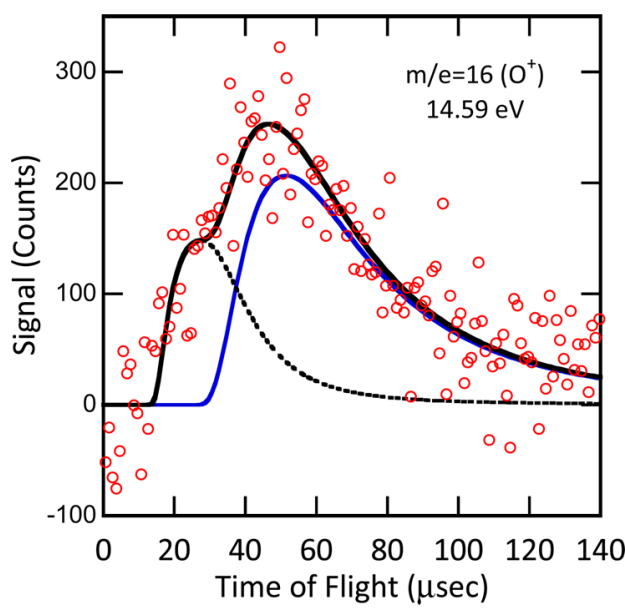

Figure 25. Time-of-flight spectrum taken at $m / e=16\left(\mathrm{O}^{+}\right)$at a source angle of $10^{\circ}$ and a photoionization energy of $14.59 \mathrm{eV}$. Data are shown in red circles. The contribution from secondary photodissociation of $\mathrm{NO}_{2}$ products formed from primary $\mathrm{C}-\mathrm{NO}_{2}$ photofission is shown as the short dash black line and uses the $P\left(E_{\mathrm{T}}, 2^{\circ}\right)$ in the Supporting Information as Figure S17. The NO formed from the unimolecular dissociation of $\mathrm{NO}_{2}$ products formed from primary $\mathrm{C}-\mathrm{NO}_{2}$ photofission is show as the solid blue line fit and it uses the $P\left(E_{\mathrm{T}}, 2^{\circ}\right)$ shown in the Supporting Information as Figure S18.

our previous study, the new $m / e=16$ TOF spectrum provides evidence for this channel's occurrence.

\section{DISCUSSION}

This study demonstrates that, upon irradiation with $193 \mathrm{~nm}$ photons, 2-bromo-2-nitropropane undergoes four different photodissociation pathways: $\mathrm{NO}_{2}$ loss, $\mathrm{HONO}$ elimination, $\mathrm{Br}$ loss, and $\mathrm{HBr}$ elimination. Although all four of these pathways were determined in our previous study on this system, ${ }^{22}$ there was significant uncertainty in the translational energy distribution for the $\mathrm{C}-\mathrm{Br}$ photofission and $\mathrm{HBr}$ photoelimination pathways. This uncertainty was due in large part to limited detection schemes and the inability to remove contributions arising from dissociative ionization processes. The new data taken on the scattering apparatus at the NSRRC along with the REMPI detection of bromine atoms presented herein have determined these and other $P\left(E_{\mathrm{T}}\right)$ 's with much more certainty.

The primary $\mathrm{HBr}$ elimination $P\left(E_{\mathrm{T}}\right)$ determined previously ${ }^{22}$ was extremely slow and only ranged from $\sim 0$ to $12 \mathrm{kcal} / \mathrm{mol}$. The $P\left(E_{\mathrm{T}}\right)$ determined in the new study is significantly faster and ranges from 0 to $40 \mathrm{kcal} / \mathrm{mol}$. The new $P\left(E_{\mathrm{T}}\right)$ has been confirmed with all available data. Along with the new $P\left(E_{\mathrm{T}}\right)$, we discovered that there were cofragments to $\mathrm{HBr}$ (2-nitropropene) that were stable and did not undergo further neutral unimolecular dissociation processes. This demonstrates that the $\mathrm{HBr}$ fragments have significant vibrational energy after the photodissociation, although we could not characterize the energetics of the $\mathrm{HBr}$ fragments directly.

The translational energy distribution for the $\mathrm{C}-\mathrm{Br}$ photofission pathway is of particular interest because it shows three distinct contributions. Both the $\mathrm{C}-\mathrm{Br}$ photofission $P\left(E_{\mathrm{T}}\right)$ 's derived from REMPI detection and the one derived from the $m / e=79\left(\mathrm{Br}^{+}\right)$TOF spectrum taken at $11.7 \mathrm{eV}$ are well represented by three Gaussian functions (Figure 26); note that the $P\left(E_{\mathrm{T}}\right)$ 's have been smoothed for easier comparison. There is additional signal on the high kinetic energy side of the $\mathrm{C}-\mathrm{Br}$

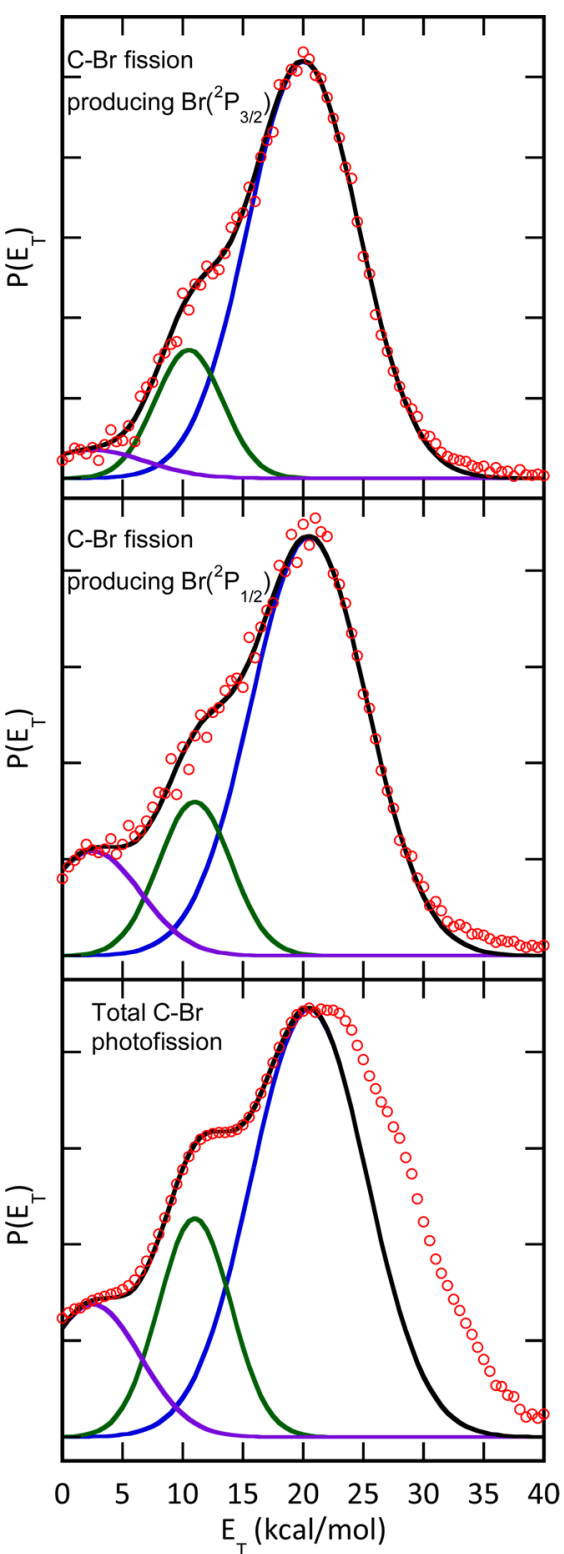

Figure 26. Comparison of all three $P\left(E_{\mathrm{T}}\right)$ 's for primary $\mathrm{C}-\mathrm{Br}$ photofission derived in this study. Top frame: REMPI $P\left(E_{\mathrm{T}}\right)$ for $\operatorname{Br}\left({ }^{2} \mathrm{P}_{3 / 2}\right)$. Middle frame: REMPI $P\left(E_{\mathrm{T}}\right)$ for $\operatorname{Br}\left({ }^{2} \mathrm{P}_{1 / 2}\right)$. Bottom frame: $P\left(E_{\mathrm{T}}\right)$ derived via forward convolution of the entirety of the signal in the $m / e=79$ TOF shown in Figure 5. The blue, green, and purple line fits represents Gaussian functions which were created for each $P\left(E_{\mathrm{T}}\right)$; the $\operatorname{Br}\left({ }^{2} P_{1 / 2}\right)$ and total $\mathrm{C}-\mathrm{Br} P\left(E_{\mathrm{T}}\right)$ are fit with the same Gaussian functions (middle and lower frame).

photofission $P\left(E_{\mathrm{T}}\right)$ derived from the $11.7 \mathrm{eV}$ data taken at the NSRRC. This may be due to a small amount of multiphoton absorption. Though all three $P\left(E_{\mathrm{T}}\right)$ 's seem to have the same trimodality, all three have different ratios between the three (i.e., Br* has a larger amount of slow signal). The peaks of the three Gaussians show that the speeds for the two spin-orbit states of bromine are extremely close to each other. In fact, the excited spin-orbit bromine tends to be faster by $\sim 1-2 \mathrm{kcal} /$ mol for each peak. This implies that the amount of energy partitioned into translation does not change on the basis of the total amount of available energy in the system. Although this is quite strange for $\mathrm{C}-\mathrm{Br}$ photofission pathways, Saha et al. ${ }^{21}$ performed the photodissociation of 2-bromo-2-nitropropane at 
$234 \mathrm{~nm}$ and found that the two spin-orbit states were very close in kinetic energy and additionally showed that the excited state has slightly more kinetic energy. There are no data available on the photodissociation at $193 \mathrm{~nm}$, however.

Translational energy distributions for photodissociation processes that possess multiple peaks usually indicate that the fragments are being formed in different electronic states; the extra energy being partitioned into these states is reflected by the lower amount of energy available to translation, as evidenced by the $P\left(E_{\mathrm{T}}\right)$ 's. To estimate the energies of the excited electronic states of the 2-nitro-2-propyl radical (the cofragment to $\mathrm{Br}$ ), we performed EOM-CCSD calculations at the $6-311++\mathrm{g}(3 \mathrm{df}, 2 \mathrm{p})$ level. After $\mathrm{C}-\mathrm{Br}$ photofission, the resulting 2-nitro-2-propyl radical possesses $C_{2 v}$ symmetry and has three low lying excited states: $2.47 \mathrm{eV}\left(\mathrm{B}_{2}\right), 2.81 \mathrm{eV}\left(\mathrm{A}_{2}\right)$, and $3.06 \mathrm{eV}\left(\mathrm{B}_{1}\right)$. Because the fastest peak in the $\mathrm{C}-\mathrm{Br} P\left(E_{\mathrm{T}}\right)$ appears to be quite similar to the $P\left(E_{\mathrm{T}}\right)$ observed in other bromoalkanes for the formation of ground electronic state products, it is probable that this represents dissociation of 2bromo-2-nitropropane into ground state radical products. If this is the case, the two slower peaks would represent the two lowest excited states $(2.47$ and $2.81 \mathrm{eV})$. Although the calculated onset of these states is not reflected perfectly in the slower translational energy distributions, it is probable that a significant amount of vibrational energy would be partitioned into the $\mathrm{NO}_{2}$ group and therefore may not be available to electronic excitation. Because both excited states of 2-nitro-2propyl radical would likely relax to the ground state nonradiatively on a very short time scale, all of the energy should be available for eventual unimolecular dissociation pathways.

The use of synchrotron radiation as tunable VUV has allowed us to further dissect the photodissociation pathways of 2-bromo-2-nitropropane at $193 \mathrm{~nm}$; it allowed the definite detection of $\mathrm{HONO}$ at $m / e=47\left(\mathrm{HONO}^{+}\right)$and the detection of the mass 71 cofragment to $\mathrm{OH}$ arising from the dissociation of 2-nitro-2-propyl radical. The three apparatuses used in this study also show extremely good experimental agreement. This new study solidifies many of the assumptions made in our previous study, ${ }^{22}$ confirming all of the four primary photodissociation pathways and all but one of the 13 secondary dissociation channels (we showed the $\mathrm{H}$ atom loss from the 2nitro-2-propyl radical does not occur). Furthermore, though almost all of the $P\left(E_{\mathrm{T}}\right)$ 's for these channels changed between the old and new study, the overall dissociation pathways remain the same. The appearance of a trimodal $\mathrm{C}-\mathrm{Br}$ photofission $P\left(E_{\mathrm{T}}\right)$ is of particular interest because most bromoalkane species only dissociate via the repulsive state to bromine and ground electronic state alkyl radical giving a well-defined fast $P\left(E_{\mathrm{T}}\right)$. It is highly probable that other halonitroalkanes may also exhibit the formation of bromine with excited state radicals due to the conserved nature of the nitro functionality. Further studies into the photodissociation of halonitroalkanes may provide insight into the effects that the nitro group has on the excited electronic states of nitroalkyl radicals.

\section{ASSOCIATED CONTENT}

\section{S Supporting Information}

Additional fits to the data taken at the NSRRC are presented in the Supporting Information, along with additional velocity map imaging data described in the text. We also refit most of the TOF spectra taken on the Chicago scattering apparatus with electron bombardment detection, data originally reported in ref
22, using the $P\left(E_{\mathrm{T}}\right)$ 's determined in this paper. Those fits provide an important consistency check, and so are included in the Supporting Information. This material is available free of charge via the Internet at http://pubs.acs.org.

\section{AUTHOR INFORMATION}

\section{Corresponding Author}

*L. J. Butler: e-mail, L-Butler@uchicago.edu; phone, 773-7027206.

\section{Notes}

The authors declare no competing financial interest.

\section{ACKNOWLEDGMENTS}

This material is based upon work supported by the U.S. Army Research Laboratory and the U.S. Army Research Office under contract number W911NF-14-1-0244. Synchrotron beam time and additional funding were provided by the National Synchrotron Radiation Research Center and Academica Sinica. We gratefully acknowledge the assistance of Dr. Bing Jin, who joined the UChicago Ph.D. students for the data acquisition runs at the NSRRC.

\section{REFERENCES}

(1) Zhang, Y.-X.; Bauer, S. H. Gas-phase Decomposition Mechanisms of $\mathrm{C}-\mathrm{NO}_{2}, \mathrm{~N}-\mathrm{NO}_{2}$ Energetic Materials: Reevaluations. Int. J. Chem. Kinet. 1999, 31, 655-673.

(2) Guo, Y. Q.; Greenfield, M.; Bhattacharya, A.; Bernstein, E. R. On the Excited Electronic State Dissociation of Nitramine Energetic Materials and Model Systems. J. Chem. Phys. 2007, 127, 154301.

(3) Guo, Y. Q.; Bhattacharya, A.; Bernstein, E. R. Excited Electronic State Decomposition of Furazan Based Energetic Materials: 3,3Diamino-4,4-Azoxyfurazan and its Model Systems, Diaminofurazan and Furazan. J. Chem. Phys. 2008, 128, 034303.

(4) Bhattacharya, A.; Guo, Y. Q.; Bernstein, E. R. Unimolecular Decomposition of Tetrazine-N-Oxide Based High Nitrogen Content Energetic Materials from Excited Electronic States. J. Chem. Phys. 2009, 131, 194304.

(5) Yu, Z.; Bernstein, E. R. Decomposition of Pentaerythritol Tetranitrate $\left[\mathrm{C} \mathrm{CH}_{2} \mathrm{ONO}_{2}\right.$ ] following Electronic Excitation. J. Chem. Phys. 2011, 135, 154305.

(6) Garland, N. L.; Nelson, H. H. Laser-Induced Decomposition of TNAZ. J. Phys. Chem. B 1998, 102, 2663-2667.

(7) Alavi, S.; Reilly, L. M.; Thompson, D. L. Theoretical Predictions of the Decomposition Mechanism of 1,3,3-Trinitroazetidine TNAZ. J. Chem. Phys. 2003, 119, 8297-8304.

(8) Anex, D. S.; Allman, J. C.; Lee,Y. T. Studies of Initial Dissociation Processes in 1,3,3-Trinitroazetidine by Photofragmentation Translational Spectroscopy. In Chemistry of Energetic Materials; Olah, G. A., Squire, D. R., Eds.; Academic Press: New York, 1991; pp 27-54.

(9) Veals, J. D.; Thompson D. L. Thermal Decomposition of 1,3,3Trinitroazetidine(TNAZ): A DFT and Ab Initio Study. J. Chem. Phys. 2014, Submitted.

(10) Greenblatt, G. D.; Zuckermann, H.; Haas, Y. OH Production in the Collision-free UV Photolysis of Aliphatic Nitro Compounds. Chem. Phys. Lett. 1987, 134, 593-599.

(11) Kwok, W. M.; Hung, M. S.; Phillips, D. L. Femtosecond Photodissociation Dynamics of Nitroethane and 1-Nitropropane in the Gas and Solution Phases from Resonance Raman Intensity Analysis. Mol. Phys. 1996, 88, 517-531.

(12) Mialocq, J. C.; Stephenson, J. C. Picosecond laser-induced fluorescence study of the Collisionless Photodissociation of Nitrocompounds at $266 \mathrm{~nm}$. Chem. Phys. 1986, 106, 281-291.

(13) Park, M. S.; Jung, K.-H.; Upadhyaya, H. P.; Volpp, H.-R. The Dynamics of Oxygen Atom Formation in the UV Photodissociation of Nitromethane. Chem. Phys. 2001, 270, 133-139. 
(14) Radhakrishnan, G.; Parr, T.; Wittig, C. Multiple Product Channels in the Collision-free UV Photodissociation of 2-Nitropropane. Chem. Phys. Lett. 1984, 111, 25-32.

(15) Wade, E. A.; Reak, K. E.; Li, S. L.; Clegg, S. M.; Zou, P.; Osborn, D. L. Time-dependent Infrared Emission Following Photodissociation of Nitromethane and Chloropicrin. J. Phys. Chem. A 2006, 110, 44054413.

(16) Yue, X.-F.; Sun, J.-L.; Wei, Q.; Yin, H.-M.; Han, K.-L. Photodissociation Dynamics of Nitromethane and Nitroethane at 266 nm. Chin J. Chem. Phys. 2007, 20, 401-406+ii.

(17) Hause, M. L.; Herath, N.; Zhu, R.; Lin, M. C.; Suits, A. G. Roaming-mediated Isomerization in the Photodissociation of Nitrobenzene. Nat. Chem. 2011, 3, 932-937.

(18) Sengupta, S.; Indulkar, Y.; Kumar, A.; Dhanya, S.; Naik, P. D.; Bajaj, P. N. Photodissociation Dynamics of 2-Nitropropane and 2Methyl-2-nitropropane at 248 and $193 \mathrm{~nm}$. J. Phys. Chem. A 2008, 112, 12572-12581.

(19) Moss, D. B.; Trentelman, K. A.; Houston, P. L. 193 nm Photodissociation Dynamics of Nitromethane. J. Chem. Phys. 1992, 96, 237-247.

(20) Butler, L. J.; Krajnovich, D.; Lee, Y. T. The Photodissociation of Nitromethane at $193 \mathrm{~nm}$. J. Chem. Phys. 1983, 79, 1708-1722.

(21) Saha, A.; Kawade, M.; Upadhyaya, H. P.; Kumar, A.; Naik, P. D. Laser-induced UV Photodissociation of 2-Bromo-2-nitropropane: Dynamics of $\mathrm{OH}$ and Br Formation. J. Chem. Phys. 2011, 134, 044316.

(22) Booth, R. S.; Lam, C.-S.; Brynteson, M. D.; Wang, L.; Butler, L. J. Elucidating the Decomposition Mechanism of Energetic Materials with Di-Nitro Functional Groups Using 2-Bromo-2-Nitropropane Photodissociation. J. Phys. Chem. A 2013, 117, 9531-9547.

(23) Ratliff, B. J.; Alligood, B. W.; Butler, L. J.; Lee, S.-H.; Lin, J. J.-M. Product Branching from the $\mathrm{CH}_{2} \mathrm{CH}_{2} \mathrm{OH}$ Radical Intermediate of the $\mathrm{OH}+$ Ethene Reaction. J. Phys. Chem. A 2011, 115, 9097-9110.

(24) Lin, J. J.; Chen, Y.; Lee, Y. Y.; Lee, Y. T.; Yang, X. Photodissociation Dynamics of $\mathrm{CH}_{3} \mathrm{Cl}$ at $157.6 \mathrm{~nm}$ : Evidence for $\mathrm{CH}_{2}\left(\tilde{\mathrm{X}}^{3} \mathrm{~B}_{1} / \tilde{\mathrm{a}}^{1} \mathrm{~A} 1\right)+\mathrm{HCl}$ Product Channels. J. Chem. Phys. Lett. 2002, 361, 374-382.

(25) Lee, S.-H.; Lee, Y.-Y.; Lee, Y. T.; Yang, X. Photodissociation Dynamics of Propene at $157.6 \mathrm{~nm}$ : Kinetic Energy Distributions and Branching Ratios. J. Chem. Phys. 2003, 119, 827-838.

(26) Daly, N. R. Scintillation Type Mass Spectrometer Ion Detector. Rev. Sci. Instrum. 1960, 31, 264-267.

(27) CMLAB2, version 6/93, modified by J. D. Myers. This is an interactive version built on the original cmlab2 program: $\mathrm{X}$. Zhao, Ph.D. dissertation, University of California, 1988.

(28) Lee, Y. T.; McDonald, J. D.; Lebreton, P. R.; Herschbach, D. R. Molecular Beam Reactive Scattering Apparatus with Electron Bombardment Detector. Rev. Sci. Instrum. 1969, 40, 1402-1408.

(29) Eppink, A. T. J. B.; Parker, D. H. Velocity Map Imaging of Ions and Electrons Using Electrostatic Lenses: Application in Photoelectron and Photofragment Ion Imaging of Molecular Oxygen. Rev. Sci. Instrum. 1997, 68, 3477-3484.

(30) Chang, B.; Hoetzlein, R. C.; Mueller, J. A.; Geiser, J. D.; Houston, P. L. Improved Two-Dimensional Product Imaging: The Real-Time Ion-Counting Method. Rev. Sci. Instrum. 1998, 69, 16651670.

(31) Chandler, D. W.; Houston, P. L. Two-Dimensional Imaging of State-Selected Photodissociation Products Detected by Multiphoton Ionization. J. Chem. Phys. 1987, 87, 1445-1447.

(32) Ratliff, B. J.; Tang, X.; Butler, L. J.; Szpunar, D. E.; Lau, K. Determining the $\mathrm{CH}_{3} \mathrm{SO}_{2} \rightarrow \mathrm{CH}_{3}+\mathrm{SO}_{2}$ Barrier from Methylsulfonyl Chloride Photodissociation at $193 \mathrm{~nm}$ Using Velocity Map Imaging. J. Chem. Phys. 2009, 131, 044304.

(33) Tang, Y.; Ji, L.; Tang, B.; Zhu, R.; Zhang, S.; Zhang, B. Studies on Photodissociation of Alkyl Bromides at 234 and $267 \mathrm{~nm}$. Chem. Phys. Lett. 2004, 392, 493-497.

(34) Kim, Y. S.; Jung, Y.-J.; Kang, W.; Jung, K.-H. Photoelectron Imaging Spectroscopy for $(2+1)$ Resonance-enhanced Multiphoton Ionization of Atomic Bromine. Bull. Korean Chem. Soc. 2002, 23, 189194.
(35) Chen, Y.; Pei, L.-S.; Jin, J.; Ran, Q.; Chen, C.-X.; Yu, S.-Q.; Ma, $\mathrm{X}$.X. Resonance-enhanced Multiphoton Ionization Spectra of the Halogen Atoms. Chin. Phys. 1999, 8, 490-495.

(36) Curtiss, L. A.; Redfern, P. C.; Raghavachari, K. Gaussian-4 theory. J. Chem. Phys. 2007, 126, 084108.

(37) Frisch, M. J.; Trucks, G. W.; Schlegel, H. B.; Scuseria, G. E.; Robb, M. A.; Cheeseman, J. R.; Scalmani, G.; Barone, V.; Mennucci, B.; Petersson, G. A.; et al. Gaussian 09, Revision A.02; Gaussian, Inc.: Wallingford, CT, 2009.

(38) Hayes, T. R.; Wetzel, R. C.; Freund, R. S. Absolute ElectronImpact-Ionization Cross-Section Measurements of the Halogen Atoms. Phys. Rev. A 1987, 35, 578-584.

(39) Vinodkumar, M.; Dave, R.; Bhutadia, H.; Antony, B. K. Electron Impact Total Ionization Cross Sections for Halogens and Their Hydrides. Int. J. Mass. Spectrom. 2010, 292, 7-13.

(40) NIST Mass Spectrometry Data Center (http://webbook.nist. gov). 